\title{
Atropselective Disposition of 2,2',3,4',6-Pentachlorobiphenyl (PCB 91) and Identification of Its Metabolites in Mice with Liver-specific Deletion of Cytochrome P450 Reductase
}

Xianai Wu, Guangshu Zhai, Jerald L. Schnoor, Hans-Joachim Lehmler

Submitted date: 03/06/2019 Posted date: 04/06/2019

Licence: CC BY-NC-ND 4.0

Citation information: Wu, Xianai; Zhai, Guangshu; Schnoor, Jerald L.; Lehmler, Hans-Joachim (2019):

Atropselective Disposition of 2,2',3,4',6-Pentachlorobiphenyl (PCB 91) and Identification of Its Metabolites in Mice with Liver-specific Deletion of Cytochrome P450 Reductase. ChemRxiv. Preprint.

Cytochrome P450 enzymes oxidize chiral polychlorinated biphenyls (PCBs) to hydroxylated metabolites. Here we investigated the role of an impaired hepatic metabolism in the disposition of PCB 91 (CASRN 68194-05-8) in mice with a liver-specific deletion of the cpr gene (KO mice). KO mice and wild type (WT) mice were exposed to racemic PCB 91. Levels and enantiomeric fractions of PCB 91 and its metabolites were determined in tissues 3-days after PCB exposure. PCB 91 were higher in KO compared to WT mice. The liver of $\mathrm{KO}$ mice accumulated PCB 91 due to the high fat content in the liver of KO mice.

2,2',3,4',6-Pentachlorobiphenyl-5-ol was the major metabolite detected in all samples. PCB 91 and its metabolites displayed a genotype-dependent atropisomeric enrichment. These differences in atropselective disposition of PCB 91 and its metabolites are consistent with slower metabolism of PCB 91 in KO than WT mice and the accumulation of the parent PCB in the fatty liver of KO mice.

File list (2)

PCB 91 manuscript 2019.pdf (691.20 KiB)

view on ChemRxiv - download file

SI PCB91 dispostion study in CPR null mice 06-03-201... (139.98 KiB) view on ChemRxiv • download file 


\section{Atropselective Disposition of 2,2',3,4',6-Pentachlorobiphenyl}

5

6

7

15 Corresponding Author:

16 Dr. Hans-Joachim Lehmler

17 The University of Iowa

18 Department of Occupational and Environmental Health

19 University of Iowa Research Park, B164 MTF

20 Iowa City, IA 52242-5000

21 Phone: (319) 335-4981

22 Fax: (319) 335-4290

23 e-mail: hans-joachim-lehmler@uiowa.edu

City, IA, 52242, USA 
24 TOC GRAPHIC

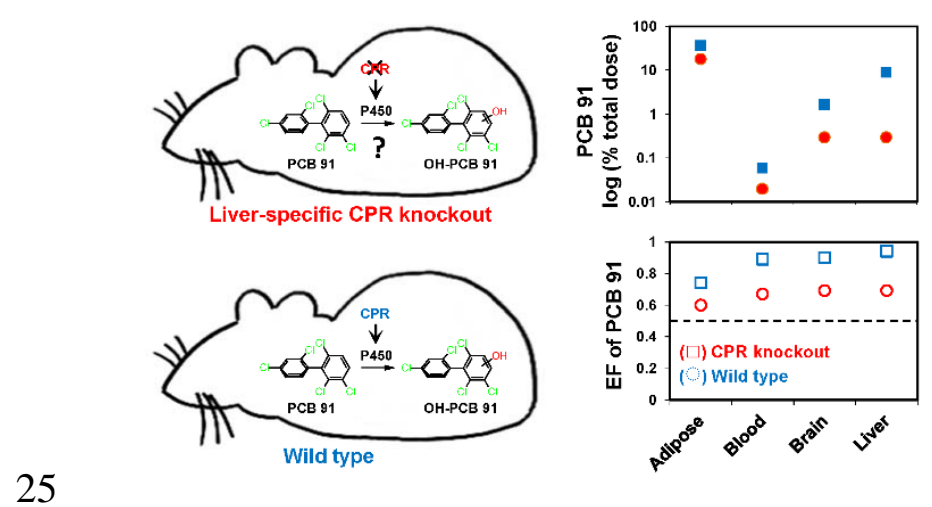


ABSTRACT

Hepatic cytochrome P450 enzymes atropselectively metabolize chiral, neurotoxic polychlorinated biphenyls (PCBs) to potentially toxic hydroxylated metabolites (OH-PCBs). Transgenic animal models with impaired metabolism of PCBs are one approach to study how the atropselective oxidation of PCBs to OH-PCB metabolites contributes to toxic outcomes, such as neurodevelopmental disorders, following PCB exposure. We investigated the disposition of PCB 91, an environmentally relevant, para substituted PCB congener, in mice with a liver-specific deletion of the cpr gene (KO mice). KO mice and congenic wild type (WT) mice were exposed orally to racemic PCB 91 (30 mg/kg b.w.). Levels and enantiomeric fractions of PCB 91 and its hydroxylated metabolites were determined in tissues and excreta three days after PCB exposure. considerable percent of the total PCB 91 dose (\%TD) was excreted with the feces as 5-91 (23

41 \%TD and 31 \%TD in KO and WT mice, respectively). We tentatively identified glucuronide and 42 sulfate metabolites present in urine samples. The PCB 91 atropisomer eluting first on the chiral column (E - $_{1}$ CB 91) displayed genotype-dependent atropisomeric enrichment, with a more

44 pronounced atropisomeric enrichment observed in WT compared to KO mice. E1-atropisomers of 5-91 and 2,2',3,4',6-pentachlorobiphenyl-4-ol (4-91) were enriched in blood and liver,

46 irrespective of the genotype; however, the extent of the enrichment of $E_{1}-5-91$ was genotype 47 dependent. These differences in atropselective disposition are consistent with slower metabolism of PCB 91 in KO compared to WT mice and the accumulation of the parent PCB in the fatty

49 liver of $\mathrm{KO}$ mice. 
INTRODUCTION

51 PCBs were produced by chlorination of biphenyl, resulting in complex mixtures of

52 structurally diverse PCB congeners. These mixtures were manufactured for a range of technical

53 applications, including as dielectric fluids in transformers and capacitors. Depending on the

54 degree of chlorination, the content of individual PCB congeners differs across PCB mixtures. For

55 example, Aroclors, technical PCB mixtures manufactured and sold in the United States, contain

56 anywhere from zero to one percent by weight of PCB 91. Approximately 1,000 metric tons of

57 this PCB congener were produced globally. ${ }^{1}$ The production of PCBs was banned in the United

58 States in the late 1970s due to environmental and human health concerns. However, PCBs are

59 inadvertent byproducts of industrial processes and, as a result, can still be found in consumer

60 products, including paint pigments ${ }^{2,3}$ and polymer resins. ${ }^{4}$ PCBs persist in the environment

61 because of their resistance to chemical and thermal degradation, and bioaccumulate and

62 biomagnify in aquatic and terrestrial food chains. Because cytochrome P450 enzymes readily

63 metabolize lower chlorinated PCB congeners to OH-PCBs, ${ }^{1,5,6}$ these PCB congeners have low

64 detection frequencies in human biomonitoring studies; however, humans are continuously

65 exposed to these congeners.

Epidemiological and animal studies implicate exposure to PCBs in a range of adverse

67 health outcomes, including neurodevelopmental disorders. ${ }^{7}$ In particular, PCB congeners with

68 several ortho chlorine substituents are sensitizers of ryanodine receptors (RyRs), ${ }^{8,9}$ intracellular

69 calcium channels implicated in PCB-induced developmental neurotoxicity. ${ }^{10}$ Other proposed

70 mechanisms of PCB neurotoxicity include altered neurotransmitter and calcium homeostasis,

71 oxidative stress, and effects on the thyroid hormone system. ${ }^{11,12}$ A recent study demonstrates

72 that PCBs' effects on RyRs, but not the thyroid hormone receptor are drivers of adverse 
73 neurodevelopmental outcomes following PCB exposure. ${ }^{13}$ There is also evidence that PCB

74 metabolites, in particular OH-PCBs, are toxic to the developing brain. OH-PCBs are potent

75 sensitizers of RyRs ${ }^{9,14}$ and can be present in the rodent brain. ${ }^{15,16}$ Moreover, animal studies

76 reveal adverse neurobehavioral outcomes following developmental exposure to OH-PCBs. ${ }^{17} 18$

77 The oxidation of PCBs by cytochrome P450 enzymes forms OH-PCBs. PCB congeners

78 without para chlorine substituents are more readily metabolized than PCB congeners with a para

79 substituent. PCB 91, a PCB congener with a para chlorine substituent, is preferentially oxidized

80 to a 1,2-shift metabolite with the hydroxy group in the meta position by human liver microsomes

81 (HLMs). ${ }^{19,} 20$ Compared to PCB 91, distinctively different metabolite profiles are observed from

82 PCB 95 (2,2',3,5',6-pentachlorobiphenyl) and PCB 136 (2,2',3,3',6,6'-hexachlorobiphenyl), PCB

83 congeners without a para chlorine substituent, in metabolism studies with HLMs. ${ }^{19,21-23}$ In

84 rodents, CYP2B enzymes play an important role in the metabolism of neurotoxic PCBs to meta

85 hydroxylated OH-PCBs. ${ }^{1}{ }^{24}$ A considerable percent of the total dose of PCB 136 is excreted as a

86 meta hydroxylated metabolite with the feces of PCB exposed mice. ${ }^{25}$ These studies typically

87 employed liver microsomes or liver tissue slices obtained from animals pretreated with

88 phenobarbital, an inducer of hepatic CYP2B enzymes. Until now, the disposition of OH-PCBs in

89 rodents and humans exposed to structurally diverse, ortho chlorinated PCBs (e.g., PCB 91) has

90 received little attention.

91 PCB 91, like several other RyR-active PCBs and OH-PCBs, displays axial chirality. The

92 presence of three or four ortho chlorine substituents hinders the rotation around the phenyl-

93 phenyl bond. Consequently, PCB 91 and its metabolites exist as two rotational isomers, or

94 atropisomers, that are non-superimposable mirror images of each other. The atropselective

95 metabolism of chiral PCBs results in an atropisomeric enrichment of the parent PCBs and their 
96 metabolites. ${ }^{1,26}$ This enrichment has toxicological implications because atropisomers can display

97 different biological effects. For example, several studies have demonstrated atropselective effects

98 of PCB 95 and PCB 136 atropisomers on RyRs and neuronal connectivity in primary neurons, ${ }^{27-}$

$99 \quad{ }^{29}$ endpoints implicated in PCB developmental neurotoxicity. It is likely that the atropisomers of

100 OH-PCBs and other PCB metabolites also display atropselective toxicities; however, this

101 hypothesis has not been investigated to-date.

102 Overall, the available evidence demonstrates that PCB and OH-PCBs atropisomers are

103 present in the developing brain and affect cellular targets implicated in PCB developmental

104 neurotoxicity, most likely in an atropselective manner. Therefore, it is important to assess how

105 the atropselective oxidation of PCBs to OH-PCB metabolites contributes to neurotoxic outcomes

106 on PCB exposed rodents and humans. The use of transgenic animal models with impaired

107 hepatic metabolism of PCBs is one possible approach to address this question. Here, we

108 investigate the atropselective disposition of PCB 91 in a well-established mouse model with a

109 liver-specific deletion of the $c p r$ gene (KO mice). ${ }^{30,31}$ Our findings reveal genotype-dependent

110 differences in the disposition of PCB 91 and its metabolites resulting from an impaired hepatic

111 metabolism and the higher fat content in the liver and feces of KO compared to congenic WT

112 mice.

113

114 EXPERIMENTAL SECTION

115 Analytical standards. 2,3,4',5,6-Pentachlorobiphenyl (PCB 117), 2,2',3,4,4',5,6,6'-

116 octachlorobiphenyl (PCB 204) and 2,3,3',4,5,5'-hexachlorobiphenyl-4'-ol (4'-159) were obtained

117 from AccuStandard (New Haven, CT, USA). 2,2',3,4',6-Pentachlorobiphenyl (PCB 91) and the

118 corresponding OH-PCB metabolites were synthesized as described earlier. ${ }^{32}$ The chemical 
119 structures and abbreviations of the PCB 91 metabolites are shown in Figure 1. Diazomethane

120 was synthesized as a solution in diethyl ether from N-methyl-N-nitroso-p-toluenesulfonamide

121 (Diazald) with an Aldrich mini Diazald apparatus (Milwaukee, WI, USA).

122 Animals. The Institutional Animal Care and Use Committee of the University of Iowa 123 approved all animal procedures (protocol \#: 1206120). Alb-Cre ${ }^{+/ /} / \mathrm{Cpr}^{\text {lox }+/+}$ mice with a liver-

124 specific deletion of the cytochrome P450 oxidoreductase gene (KO mice) and Alb-Cre ${ }^{-/-} / \mathrm{Cpr}$

$125^{\text {lox }+/+}$ mice (WT mice) were obtained from Dr. Xinxin Ding (School of Public Health, State

126 University of New York, Albany, NY). Mice were maintained as described in the Supporting

127 Information (also, see references ${ }^{30,31}$ ). To study the disposition of racemic PCB 91, female KO

128 and WT mice (age 12 to 13 weeks; Table S1) were randomly divided into treatment and control

129 groups. WT (n=3) and KO (n=4) mice received a single oral dose PCB 91 (30 mg/kg b.w.) on a

130 Vanilla Wafer cookie (7.5 g/kg b.w.). ${ }^{33}$ This route of administration was selected to reduce the

131 stress of the animal and to facilitate a comparison with similar disposition studies in mice. ${ }^{25}$, 33-36

132 WT (n=2) and KO (n=2) control groups received the vehicle (Vanilla Wafer cookie; $7.5 \mathrm{~g} / \mathrm{kg}$

133 b.w.) alone and were used to assess potential background contamination with PCB 91 and its

134 metabolites. After eating the entire cookie, animals were transferred to metabolic cages, and

135 urine and feces were collected daily for three days. The two KO mice exposed to vehicle were

136 housed together. All other mice were housed individually. Mice were euthanized by carbon

137 dioxide asphyxiation followed by cervical dislocation three days after PCB 91 administration.

138 Blood and tissues (brain, liver, and adipose tissue) were collected, and their wet weights were

139 determined (Table S1). All samples were stored at $-80^{\circ} \mathrm{C}$ until further analysis. A discussion of

140 phenotypes of KO vs. WT mice is provided in the Supporting Information. 
142 samples. PCB 91 and its metabolites were extracted by pressurized liquid extraction from liver

143 (0.57-0.93 g), brain (0.18-0.30 g), adipose (0.06-0.34 g), and feces samples (0.29-0.35g) using a

144 Dionex ASE200 system (Dionex, Sunnyvale, CA). ${ }^{33}$ Briefly, the tissues were mixed with 145 diatomaceous earth (2 g; Dionex) and placed in the extraction cell (33 mL) containing Florisil 146 (60 100 mesh, 12 g; Fisher Scientific). PCB 117 (500 ng) and 4'-159 (137 ng) were added to 147 each sample as surrogate recovery standards, and the cells were extracted with hexane148 dichloromethane-methanol (48:43:9, v/v/v) at $100{ }^{\circ} \mathrm{C}$ and 1500 psi (10 MPa) with pre-heat 149 equilibration for $6 \mathrm{~min}, 60 \%$ of cell flush volume, and 1 static cycle of 5 min. ${ }^{37,38}$ Sample blanks 150 containing only Florisil and diatomaceous earth were extracted in parallel with each sample set. 151 The extracts were concentrated to approximately $1 \mathrm{~mL}$ using a Turbo Vap ${ }^{\circledR}$ II (Biotage, NC, 152 USA) and transferred with hexane to glass tubes. The samples were evaporated to dryness under 153 a gentle stream of nitrogen and redissolved in $1 \mathrm{~mL}$ of hexane. After derivatization of the $\mathrm{OH}-$ 154 PCBs with a solution of diazomethane in diethyl ether, the organic extracts were subjected to a 155 sulfur clean-up step, followed by treatment with concentrated sulfuric acid as described earlier.

$156 \quad$ PCB 91 and its hydroxylated metabolites were extracted from blood samples (0.49 to 1570.87 g) by liquid-liquid extraction following a published method. ${ }^{37}$ Briefly, blood samples were 158 diluted by $3 \mathrm{~mL}$ of 1\% KCl and the surrogate recovery standards (PCB 117, 250 ng; 4'-159, 69 159 ng) were added. Each sample was acidified with $1 \mathrm{~mL}$ of $6 \mathrm{M} \mathrm{HCl}$, followed by addition of $3 \mathrm{~mL}$ 160 2-propanol and $5 \mathrm{~mL}$ hexane : $\operatorname{MTBE}(1: 1, \mathrm{v} / \mathrm{v})$. After thoroughly mixing and centrifugation, the 161 organic phase was transferred to the second tube, and each sample was extracted a second time 162 with $3 \mathrm{~mL}$ of hexane. The combined organic phases were washed with $3 \mathrm{~mL}$ of $\mathrm{KCl}$ (1\%). The 
163 samples were evaporated to dryness, derivatized with diazomethane, and further treated as 164 described above for tissue samples.

$165 \quad \beta$-Glucuronidase/sulfatase deconjugation of urine samples. Two aliquots of each urine 166 sample (approximately 0.1 to $0.6 \mathrm{~mL}$ ) were diluted with an equal volume of $0.2 \mathrm{M}$ sodium 167 acetate buffer $(\mathrm{pH}=5)$ to determine if glucuronide or sulfate conjugates of hydroxylated PCB 91 168 metabolites were present in urine samples. Both aliquots were incubated in parallel with or 169 without $\beta$-glucuronidase/sulfatase mixture (20 $\mu \mathrm{L}$; type $\mathrm{H}-2$ from Helix pomatia, 100,000 170 units/mL; Sigma-Aldrich Co. St. Louis, MO, USA) for 12 h at $37^{\circ} \mathrm{C}^{25}$ Subsequently, PCB 91 171 and its hydroxylated metabolites were extracted from urine samples as described above for 172 blood.

173 Gas chromatographic analysis of PCB 91 and its metabolites. PCB 91 and the 174 methylated derivatives of hydroxylated PCB 91 metabolites were quantified either on a DB1-MS 175 (60 m x $0.25 \mathrm{~mm}$ ID x $0.25 \mu \mathrm{m}$ film thickness; Agilent, Santa Clara, CA) or an Equity-1 176 capillary column (60 m x $0.25 \mathrm{~mm}$ ID x $0.25 \mu \mathrm{m}$ film thickness; Supelco, Bellefonte, PA) using 177 an Agilent 7890A gas chromatograph equipped with two ${ }^{63} \mathrm{Ni}-\mu \mathrm{ECD}$ detectors. ${ }^{39}$ The levels of 178 PCB and its metabolites were calculated using PCB 204 as internal standard (or volume 179 corrector) and adjusted for tissue wet weight, lipid content or expressed as \%TD (Tables S2-S6). 180 Tissue levels are reported as \%TD throughout the manuscript. The same trends in tissue levels 181 were observed when levels were adjusted for tissue wet weight or extractable lipid content.

182 Enantiomeric fractions, a measure of the atropisomeric enrichment of PCB 91 and its 183 metabolites, were determined on the same instrument described above. ${ }^{40}$ PCB 91, 4-91 and 5-91 184 atropisomers were separated using a ChiralDex BDM (BDM) column (30 m length, $250 \mu \mathrm{m}$ 185 inner diameter, $0.12 \mu \mathrm{m}$ film thickness; Supelco, St. Louis, MO). The atropisomers of PCB 91 
186

and 5-91 were separated on CP-ChiraSil-DEX CB (CD) column (30 m length, $250 \mu \mathrm{m}$ inner diameter, $0.12 \mu \mathrm{m}$ film thickness; Agilent Technologies, Santa Clara, CA). The temperature program for the atropselective analyses was as follows: $10{ }^{\circ} \mathrm{C} / \mathrm{min}$ from 100 to $140{ }^{\circ} \mathrm{C}$, hold for $535 \mathrm{~min}, 10{ }^{\circ} \mathrm{C} / \mathrm{min}$ to $200{ }^{\circ} \mathrm{C}$, and hold for $15 \mathrm{~min}$. Atropisomers of 4,5-91 $(2,2$ ',3,4',6pentachlorobiphenyl-4,5-diol) did not resolve on either atropselective column. As described previously, the elution order of PCB 91 atropisomers are inverted on the BDM and CD column (i.e., $\mathrm{E}_{1}$-PCB 91 on the BDM column and $\mathrm{E}_{2}$-PCB 91 on the CD column are the same PCB 91 atropisomer; vice versa, $\mathrm{E}_{2}-\mathrm{PCB} 91$ on the BDM column and $\mathrm{E}_{1}-\mathrm{PCB} 91$ on the CD column are the same PCB 91 atropisomer). ${ }^{41}$ If not stated otherwise, PCB 91 atropisomers are identified based on the elution order on the BDM column. The EF values of PCB 91, 4-91, and 5-91 were determined as $\mathrm{EF}=$ Area $\mathrm{E}_{(1)} /\left(\right.$ Area $_{\mathrm{E}_{(1)}}+$ Area $\left.\mathrm{E}_{(2)}\right)$ and are summarized in Table S7. For information regarding the quality assurance/quality control of the chemicals analyses, including background levels of in tissues and excreta from control animals, see the Supporting Information and Tables S8 and S9.

Extractable lipid content. Lipids were extracted from tissues and feces samples by pressurized liquid extraction as described earlier. ${ }^{33}$ Briefly, the samples were mixed with $2 \mathrm{~g}$ of diatomaceous earth and placed in $11 \mathrm{~mL}$ extraction cells. The cells were extracted with the Dionex ASE200 system mentioned above using a chloroform/methanol mixture (2:1, v/v) at 120 ${ }^{\circ} \mathrm{C}$ and 1500 psi. The lipid content was determined gravimetrically after evaporation of the solvent. The extractable lipid content of each tissue or feces is summarized in Table S10.

Conjugate identification by LC/MS/MS. In order to further identify potential glucuronide and/or sulfate conjugates of hydroxylated PCB 91 metabolites in urine (Figure 1), a urine sample, filtered through a $0.45 \mu \mathrm{m}$ filter, was analyzed on an Ascentis Express $\mathrm{C}_{18}$ column 
209 (15 cm length, $3.0 \mathrm{~mm}$ inner diameter, $5 \mu \mathrm{m}$ particle size; Supelco, St. Louis, MO) using an 210 Agilent 1260 Infinity liquid chromatograph equipped with an Agilent 6460 MS/MS detector. The

211 source parameters for the MS/MS detector were as follows: gas temp at $325^{\circ} \mathrm{C}$, gas flow at 10 $212 \mathrm{~L} / \mathrm{min}$, nebulizer at $20 \mathrm{psi}$, sheath gas temp at $400{ }^{\circ} \mathrm{C}$, sheath gas flow at $12 \mathrm{~L} / \mathrm{min}$, capillary 213 negative at $3500 \mathrm{~V}$. The mobile phases were $10 \mathrm{mM} \mathrm{NH}_{4} \mathrm{Ac}$ in water $(\mathrm{pH}=6.8)$ and acetonitrile, 214 with a flow rate at $0.3 \mathrm{~mL} / \mathrm{min}$. The concentration of acetonitrile in mobile phase increased from $21530 \%$ to $50 \%$ from 5 to $30 \mathrm{~min}$; increased to $85 \%$ from 30 to $40 \mathrm{~min}$; was maintained for $5 \mathrm{~min}$, 216 and finally decreased to $30 \%$ from 45 to $50 \mathrm{~min}$. The injection volume was $10 \mu \mathrm{L}$. MS 217 electrospray in negative ionization mode was utilized. The presence of 5-91 and 4-91 were 218 confirmed based on scan mode with a mass in the range of 100-800 amu and selective ion model 219 (SIM) with $\mathrm{m} / \mathrm{z} 341$ and retention time matched to authentic standards.

220 In order to detect unknown metabolites, such as glucuronides and sulfates, the theoretical 221 isotope ratios of 0.617:1:0.648 and a SIM method with the following $\mathrm{m} / \mathrm{z}$ were used to screen for 222 metabolites: Dihydroxylated PCB 91 conjugated with a single sulfate moiety $\mathrm{m} / \mathrm{z}$ at 434.82 , 223 436.82, and 438.82; dihydroxylated PCB 91 conjugated with a single glucuronide moiety $\mathrm{m} / \mathrm{z}$ at 224 530.89, 532.89, 534.89; hydroxylated PCB 91 conjugated with a sulfate moiety $\mathrm{m} / \mathrm{z}$ at 418.8 , 225 420.8, 422.8; and hydroxylated PCB 91 conjugated with a glucuronide moiety $\mathrm{m} / \mathrm{z}$ at 514.9, 226 516.9, 518.9. The presence of glucuronide or sulfate metabolites of PCB 91 in urine was further 227 confirmed in the multiple reaction monitoring (MRM) mode using transitions of $\mathrm{m} / \mathrm{z} 516.9>175$ 228 for hydroxylated PCB 91 glucuronides and $m / z 218.5>79$ for dihydroxylated PCB 91 sulfates. 229 Other transitions were not confirmed.

230 Statistical analyses. All data are reported as mean \pm one standard deviation. Differences

231 in levels and EF values between both genotypes were assessed using two-sample, two-tailed 
232 Student's t-test. Differences between EF values of the racemate and the samples were evaluated

233 using two-sample, one-tailed Student’s t-test. Differences were considered statistically

234 significant for $\mathrm{p}<0.05$. Changes in the concentration of OH-PCB metabolites in the urine after

$235 \beta$-glucuronidase/sulfatase treatment were assessed with interaction plots using R (Figures S1 to

236 S3). ${ }^{42}$

237

238

RESULTS

PCB 91 tissue and excreta levels. PCB 91 levels in KO mice, expressed as \%TD,

240 followed the rank order adipose $>$ liver $>$ brain $>>$ blood (Figure 2). The PCB 91 detected in

241 these four tissues accounted for approximately 55 \%TD (Table S6). In WT mice, PCB 91 levels

242 followed a similar rank order; however, the PCB 91 residue in these tissues accounted for only

24320 \%TD. Moreover, levels of PCB 91 were significantly higher in the blood, brain, liver, and

244 excreta from KO compared to WT mice (Figure 2; Table S6). PCB 91 levels in adipose tissue

245 were also higher in the adipose tissue of KO compared to WT mice; however, this difference was

246 not statistically significant. It is noteworthy that PCB 91 levels in the liver were 30-times higher

247 in KO compared to WT mice, with 9 \%TD and 0.3 \%TB of PCB 91 being retained in the liver of

248 KO and WT mice, respectively.

249 The amount of PCB 91 excreted with the feces was one order of magnitude higher in KO

250 (4 \%TD) compared to WT mice (0.4 \%TD) and decreased from day 1 to day 3. Levels of PCB

25191 decreased from 3 \%TD to 0.2 \%TD in KO mice and from 0.3 \%TD to 0.05 \%TD in WT mice

252 in this period (Figure 2). It is noteworthy that despite the larger \%TD of PCB 91 excreted with

253 the feces in KO mice, the amount of PCB 91 retained in the liver was also much higher in KO

254 compared to WT mice. This observation is consistent with impaired metabolism of PCB 91 in 
255 KO mice. The amount of PCB 91 excreted with the urine was also higher in KO compared to

256 WT mice (Figure 2). Briefly, KO mice excreted $4 \% \mathrm{TD}$, and WT mice excreted $0.3 \% \mathrm{TD}$ with

257 the urine over the three-day study period. In KO mice, the amount of PCB 91 in the urine

258 decreased from 2 \%TD on day 1 to $0.8 \% \mathrm{TD}$ on day 3. Levels of PCB 91 decreased from 0.2

259 \%TD on day 1 to $0.02 \% \mathrm{TD}$ on day 3 in the urine from WT mice.

260 Levels of OH-PCB 91 metabolites. The disposition of OH-PCB metabolites of PCB 91

261 has not been investigated in vivo to-date. We, therefore, measured the levels of the OH-PCB 91

262 metabolites shown in Figure 1 in selected tissues and excreta. Four OH-PCB 91 metabolites,

263 including 3-100 (2,2',4,4',6-pentachlorobiphenyl-3-ol; 1,2-shift product), 5-91, 4-91 and 4,5-91,

264 were detected in blood, liver, feces, and urine collected from both KO and WT mice (Figure 2;

265 Table S6). 5-91 was the major metabolites detected in blood, liver, feces, and urine, with 5-91

266 levels decreasing in the rank order feces $>$ urine $>$ liver $>$ blood. The sum of 5-91 in these four

267 compartments accounted for approximately 23 \%TD and 31 \%TD in KO and WT mice,

268 respectively (Table S6). The sum of the minor metabolites, including 3-100, 4-91 and 4,5-91, in

269 the same compartments represented only $1.1 \% \mathrm{TD}$ and $2.3 \% \mathrm{TD}$ in KO and WT mice,

270 respectively.

271 Feces was the major and urine a minor route of excretion of OH-PCB 91 metabolites

272 (Figure 3). In WT mice, the amount of 5-91 decreased from 17\%TD to $5 \% \mathrm{TD}$ in feces and 0.05

$273 \% \mathrm{TD}$ to $0.01 \% \mathrm{TD}$ in urine from day 1 to day 3. In KO mice, the amount of 5-91 decreased from

$27412 \% \mathrm{TD}$ to $4 \% \mathrm{TD}$ in feces and $0.3 \% \mathrm{TD}$ to $0.07 \% \mathrm{TD}$ in the urine. Although more OH-PCBs in

275 both excreta were generally lower in excreta from KO compared to WT mice, these differences

276 did not reach statistical significance. 
278 of phase II metabolites, aliquots of urine samples were incubated in parallel with and without 279 a $\beta$-glucuronidase/sulfatase mixture. Levels of 5-91 and 4,5-91, but not 4-91 were higher in 280 urine samples collected on day 1 to day 3 urines after deconjugation (Figure 4; Table S6, Figure 281 S1-S3). These findings provide indirect evidence that OH-PCB metabolites of PCB 91 are 282 metabolized to OH-PCB conjugates that are eliminated with the urine. Liquid chromatography283 tandem mass spectrometry (LC-MS/MS) was used to further screen for the presence of OH-PCB 28491 metabolites and their conjugates in a representative urine sample. The hydroxylated 285 metabolites of PCB 91 eluted with a retention time of $\sim 42 \mathrm{~min}$, as determined with authentic 286 standards of 4-91 and 5-91. Consistent with our quantitative analysis (Figure 3; Table S6), 5-91 287 was a major and 4-91 a minor metabolite (Figures 4A and 4B). The other two OH-PCB 91 288 metabolites could not be identified because of the low levels of these metabolites in urine 289 samples, and no authentic hydroxylated standard was available. Several OH-PCB 91 conjugates were detected at retention times $<20$ min (Figures 4C

291 and 4D). Two peaks with $\mathrm{m} / \mathrm{z}$ 514.9, 516.9 and 518.9 in an isotope ratio matching the theoretical 292 isotope ratio of a pentachlorinated compound (i.e., 0.617:1:000:648) were observed at retention 293 times of 7.538 and 13.863 min. Both peaks were tentatively identified as OH-PCB 91 294 glucuronides (Figure 4D). Analysis in the MRM mode with a transition of $\mathrm{m} / \mathrm{z} 516.8>175.0$ 295 further confirmed the identification of both metabolites as OH-PCB 91 glucuronides (Figure 296 4D). A peak of a pentachlorinated metabolite with $\mathrm{m} / \mathrm{z}$ 434.82, 436.82, and 438.82 was observed 297 at a retention time of 3.125 min (not shown). This peak corresponds to a dihydroxylated PCB 91 298 metabolite conjugated with a single sulfate moiety; however, we could not confirm the presence 299 of this metabolite in the MRM mode. 
301 atropisomeric enrichment of PCB 91 in rodents. To address this knowledge gap, we investigated

302 the genotype-dependent atropisomeric enrichment of PCB 91 in selected tissues and excreta of 303 mice (Figure 5). The PCB 91 atropisomer eluting first on the BDM column (E 1 -PCB 91) was

304 significantly enriched in adipose, blood, brain, and liver in both of KO and WT mice (Figure 5A;

305 Table S7). The same PCB 91 atropisomer was enriched in the liver, and blood samples analyzed

306 on the CD column, and the extent of the atropisomeric enrichment, determined using the EF

307 values, was comparable for analyses on both columns (Table S7). EF values of PCB 91 ranged

308 from 0.74 in adipose tissue to 0.94 in the liver of WT mice exposed to racemic PCB 91 (Table

309 S7). A less pronounced atropisomeric enrichment was observed in tissues from KO mice, with

310 EF values of PCB 91 ranging from 0.60 in adipose tissue to 0.69 in brain and liver. EF values of

311 PCB 91 followed the rank order liver $>$ brain $\sim$ blood $>$ adipose in WT mice, and liver $\sim$ brain $\sim$

312 blood > adipose in KO mice. E - $_{1}$ PCB 91 was also enriched in feces samples from all time points

313 investigated. The EF values in feces increased from day 1 to day 3. In day 3 samples, the EF

314 values of PCB 91 in feces were close to those observed in the liver (Table S7). Moreover, the

315 extent of the atropisomeric enrichment of $\mathrm{E}_{1}-\mathrm{PCB} 91$ in feces samples was less pronounced in 316 KO compared to WT mice.

317 Enantiomeric fractions of OH-PCB 91 metabolites. Atropselective analyses of 5-91

318 and 4-91 in blood and liver were performed in the BDM column (Figures 5B and 5C). Analyses

319 on the CD column confirmed the extent and direction of the atropisomeric enrichment of 5-91

320 observed on the BDM column (Table S7). E1-5-91 was enriched in blood from both KO and WT

321 mice, with more pronounced atropisomeric enrichment in WT compared to KO mice (Figure

322 5B). E 1 -5-91 was also enriched in the liver from WT mice, but the atropisomeric enrichment was 
323 less pronounced compared to blood. Near racemic chiral signature of 5-91 were observed in the

324 liver of KO mice. A marked enrichment of $E_{1}-4-91$ was observed in liver and blood from both

325 KO and WT mice, and no significant differences in EF values were found by genotype (Figure

326 5C).

In contrast to the enrichment observed in tissues, E2-5-91 was enriched in feces from KO 328 mice (Figure 5B). The atropisomeric enrichment of $E_{2}-5-91$ became less pronounces from day 1

329 to day 3, resulting in a near racemic EF value of 0.45 on day 3 in KO mice. In WT mice, $\mathrm{E}_{2}-5-91$

330 was enriched in feces samples collected on day 1 after PCB exposure, whereas $E_{1}-5-91$ was

331 enriched in feces samples collected on day 2 and day 3. As a result, the EF values of 5-91 in

332 feces samples were always significantly lower in KO mice than WT mice. E2-5-91 was enriched

333 considerably in urine samples from KO mice (all days) and WT mice (day 1 only) (Table S7).

334 Similar to feces, EF values of 5-91 in urine samples also increased from day 1 to day 3 in both

335 KO and WT mice, as determined on the CD column (Table S7). However, a more pronounced

336 atropisomeric enrichment of $E_{2}-5-91$ was observed in KO compared to WT mice.

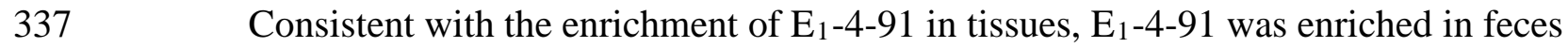

338 samples collected on days 1 to 3 . The extent of the enrichment of E $1-4-91$ increased from day 1

339 to day 3. Similar EF values were observed in day 1 feces samples from KO and WT mice.

340 Statistically significant differences in the EF values of KO compared to WT mice were found in

341 day 2 and day 3 feces samples, with a more pronounces atropisomeric enrichment of $E_{1}-4-91$

342 being present in feces samples obtained from WT mice.

DISCUSSION

Disposition of PCB 91 in KO and WT mice. In this disposition study, levels of PCB 91

346 were significantly higher in blood and tissues from female KO compared to age-matched 
congenic WT mice exposed orally to PCB 91. We observed a similar difference in the

348 disposition of PCB 136 in tissues from KO and WT exposed to racemic PCB 136 using the same 349 dosing paradigm. ${ }^{25,43}$ In both studies, a considerable percentage of the total dose of both parent 350 PCBs was accumulated in the liver of KO mice. The accumulation of PCBs, such as PCB 91, in 351 the liver of KO, but not WT mice, is an indirect result of the liver-specific deletion of $\operatorname{crp}$.

352 Briefly, KO mice have an impaired metabolism of bile acids and lipids in the liver and, 353 consequently, have livers with higher levels of extractable lipids and hepatic P450 proteins 354 compared to congenic WT mice. ${ }^{25,30,44,45}$ Studies in rats demonstrate that fatty liver results in a 355 redistribution of PCBs, such as PCB 126, from the adipose tissue to the liver, potentially with 356 higher levels of PCBs in the liver compared to adipose tissue. ${ }^{46,47}$ Other lipophilic compounds 357 also accumulate in the liver in models of non-alcoholic fatty liver disease. ${ }^{48}$ Moreover, ortho 358 chlorinated PCB congeners bind to hepatic P450 enzymes ${ }^{49}$ and, as a result, can be sequestered 359 into the liver in the absence of hepatic metabolism. Similarly, dioxin-like PCB congeners (i.e., 360 PCB 126) are retained in the rodent liver due to binding to CYP1A enzymes. ${ }^{50,51}$ Together, the 361 hepatic accumulation of PCB 91 and the impaired hepatic PCB metabolism result in changes in 362 the toxicokinetics of PCB 91 in KO compared to WT mice that, as we described recently for 363 PCB 136, ${ }^{43}$ result in higher PCB levels in blood and tissues from KO mice at later time points 364 (i.e., $72 \mathrm{~h}$ after PCB administration). Feces is a route of elimination of PCBs, such as PCB 136, in mice $25,34-36$ and rats. ${ }^{52}$

366 Typically, less than $2 \%$ of the total dose is eliminated with the feces over a three-day period in $367 \mathrm{C} 57 \mathrm{Bl} / 6$ mice exposed orally to PCBs. ${ }^{19,29-31}$ Mice exposed by oral gavage to a PCB mixture, 368 however, excreted > 10 \%TD of PCB 91 within 12 h..$^{53}$ The excretion of a higher \%TD of 369 unresorbed PCBs in this earlier study is likely due to differences in the mouse strain and the 
370 mode of administration (cookie in this study vs. oral gavage in our earlier study ${ }^{53}$ ). In the

371 present study, feces was also a route of excretion of PCB 91 in both KO and WT. Moreover,

372 there were clear differences in the extent of fecal excretion between genotypes, with KO mice

373 excreting 10-times more PCB 91 than WT mice based on the total PCB 91 dose. In contrast, only

374 5-times more PCB 136 was excreted with the feces in KO than WT mice (4.9 \%TD vs. 0.95

$375 \% \mathrm{TD}$, respectively) following oral exposure to PCB $136 .{ }^{25}$ Overall, the more pronounced fecal 376 excretion of PCB 91 and PCB 136 in KO mice is due to the higher fat content of the feces of KO

377 mice. The higher fecal fat content in KO mice has been reported previously and is the result of

378 an impaired bile acid metabolism in KO mice caused by the liver-specific deletion of $c p r$, which

379 in turn reduces the absorption of fats from the gastrointestinal tract. ${ }^{54}$ The larger amount of non-

380 resorbed fats in KO mice not only reduces the oral bioavailability of PCBs (i.e., increases their

381 elimination without absorption), ${ }^{55}$ but also increases their elimination from the gastrointestinal

382 tract (i.e., their diffusion from the bloodstream into the gastrointestinal tract). ${ }^{56}$ Our earlier PCB

383 disposition study also demonstrated that a higher fecal fat content was associated with higher

384 fecal PCB levels. ${ }^{53}$

385 The present study revealed differences in the distribution of PCB 91 and PCB 136 in KO

386 mice. We observed 60-fold higher levels of PCB 136, ${ }^{25}$ but only 30 -fold higher levels of PCB 91

387 in the liver of KO compared to WT mice. At the same time, much less PCB 136 was present in

388 the liver of exposed KO mice (4.2 \%TD of PCB 136 compared to 9 \%TD of PCB 91). The

389 differences in the hepatic accumulation of both PCB congeners are consistent with differences in

390 the toxicokinetics of both congeners that, in turn, are the result of differences in their

391 extrahepatic metabolism. To the best of our knowledge, no studies have investigated how an

392 impaired hepatic metabolism, for example, due to mutations or deficiencies in CPR expression, 
or genetic polymorphisms of P450 enzymes involved in the metabolism of PCBs (e.g., CYP2A6

394 and CYP2B6) alters the PCB profiles and levels in the human liver. It is also unknown how fatty

395 liver affects the disposition of PCBs in humans. It seems likely that congener-specific differences

396 in the distribution of PCBs in the normal versus diseased liver play an overlooked role in the

397 progression of alcoholic or non-alcoholic fatty liver disease. For example, the activation of

398 human nuclear transcription factors implicated in non-alcoholic fatty liver disease is complex

399 and highly congener specific. ${ }^{57}$ Thus, higher hepatic PCB levels are expected to alter the

400 expression of drug metabolizing enzymes in an already diseased liver, a hypothesis that warrants

401 further attention, especially considering the high global prevalence of alcoholic and non-

402 alcoholic liver disease. ${ }^{58}$

403 Disposition of OH-PCB 91 metabolites in KO and WT mice. Although a large body of 404 evidence demonstrates that PCB metabolites are toxic, ${ }^{5,6}$ only limited information about the 405 metabolism of structurally diverse PCB congeners, including PCB 91, is available. In the present 406 study, hydroxylated metabolites of PCB 91 were present in blood, liver, and excreta of KO and 407 WT mice. These observations are consistent with studies of the disposition of PCB 95 and PCB 408136 in mice. ${ }^{37,59}$ Levels of OH-PCBs were below the limit of detection in the adipose and brain 409 tissue, irrespective of the genotype. In a separate study, we reported congener-dependent $\mathrm{OH}$ 410 PCBs profiles in the brain of neonatal mice and the corresponding dams exposed

411 developmentally to racemic PCB 95 and PCB 136 via the maternal diet. ${ }^{15} \mathrm{OH}-\mathrm{PCB}$ were also

412 detected in the brain of wildlife (i.e., cetaceans ${ }^{60}$ and polar bears ${ }^{61}$ ) and rats. ${ }^{16}$ Feces was a major

413 route of excretion of OH-PCB 91 metabolites. It is noteworthy that hydroxylated PCB 91

414 metabolites accounted for 24 \%TD and 33 \%TD of PCB 91 in the feces of KO and WT mice, 415 respectively. Similarly, feces was a major and urine a minor route of excretion of hydroxylated 
416 metabolites of PCB 136 in mice. ${ }^{25}$ In contrast, two lower chlorinated PCB congeners, PCB 3 and

417 PCB 11 were rapidly eliminated as metabolites with both the urine and feces in rats exposed by 418 inhalation to the respective PCB congener. ${ }^{62-64}$

419 The distribution of OH-PCB metabolites revealed differences compared to our previous 420 study with PCB 136 in the same mouse model. ${ }^{25}$ Briefly, 5-136 accounted for 26 \%TD of PCB 421136 in WT mice in the earlier study, whereas the structurally related 5-91 accounted for 31 \%TD 422 of PCB 91 in this study. In KO mice, both meta hydroxylated metabolites accounted for a 423 comparable \%TD in the blood, liver, feces, and urine (i.e., 24 \%TD of PCB 136 vs. 23 \%TD 424 PCB 91). The \%TD of 4-136, a para hydroxylated metabolite, was 4.6-times and 3.9-time higher 425 compared to the \%TD of the structurally analogous 4-91 in KO and WT mice, respectively. 426 Unlike our previous study with PCB $136,{ }^{25}$ we observed no statistically significant differences in 427 the tissue levels of PCB 91 metabolite between WT and KO mice. In contrast, liver and blood 428 levels of OH-PCB 136 metabolites were typically significantly higher in KO compared to WT 429 mice after oral exposure to PCB $136 .{ }^{25}$ In vitro metabolism studies with precision-cut liver tissue 430 slices also demonstrate congener-specific differences in the metabolism of PCBs, with PCB 91 431 being more rapidly oxidized in meta, but not para position compared to PCB 136. These 432 differences in the metabolism of PCB 91 and PCB 136 may be toxicologically important 433 because, depending on their substitution pattern, OH-PCBs display different toxicities. ${ }^{5,6}$ $434 \quad$ OH-PCBs are further metabolized to glucuronide and sulfate metabolites in rodent 435 models ${ }^{52,62,65}$ and humans. ${ }^{66}$ Because conjugates of OH-PCBs are potential biomarkers of PCB 436 exposure, ${ }^{63}$ we screened urine samples for the presence of OH-PCB 91 conjugates. Only 5-91 437 and 4,5-91 conjugates were excreted with the urine based on our deconjugation experiments. 438 Similarly, 5-136 and 4,5-136, but not 4-136 were excreted with the urine as OH-PCB 136 
conjugates following exposure of WT and KO mice PCB $136 .{ }^{25}$ Our screening of a

440 representative urine sample by LC-MS/MS for metabolites identified an OH-PCB 91

441 glucuronide. Besides, we observed a dihydroxylated PCB 91 metabolite conjugated with a single

442 sulfate moiety; however, we could not confirm the presence of this metabolite in the MRM

443 mode. The detection of these metabolites in urine is not entirely unexpected. For examples,

444 several studies have shown the presence of mono- and di-hydroxylated PCB conjugates in urine

445 for rats exposed to lower chlorinated PCBs. ${ }^{62,63,67}$ A recent study reported complex PCB

446 metabolite profiles, including dihydroxylated PCB metabolites conjugated with a single sulfate

447 moiety, in serum from polar bears and feces from mice exposed to a complex PCB mixture. ${ }^{68}$

448 Further accurate mass determinations and MS/MS experiments are therefore warranted to

449 confirm the formation of these OH-PCB 91 metabolites and study their disposition in mice.

Atropisomeric enrichment of PCB 91 and its OH-PCB metabolites. Chiral PCBs,

451 such as PCB 91, are atropselectively oxidized by P450 enzymes, resulting in an atropisomeric

452 enrichment of both the parent PCB and its hydroxylated metabolites. ${ }^{1,26}$ Moreover, several

453 studies reveal differences in the hepatotoxicity and neurotoxicity of pure PCB atropisomers. ${ }^{26}$

454 For example, PCB 91 causes atropselective metabolic and lipidomic responses in earthworms in 455 vivo. ${ }^{69}$ Based on the elution order of PCB 91 atropisomers on the BDM column, the enrichment 456 of $\mathrm{E}_{1}$-PCB 91 in mice was consistent with in vitro studies with mouse liver tissue slices ${ }^{40}$ and 457 disposition studies in mice exposed orally to a PCB mixture containing PCB 91. ${ }^{53,70} \mathrm{E}_{1}$-PCB 91 458 was also enriched in studies with recombinant rat CYP2B1 and rat liver microsomes ${ }^{41,71,72}$ and 459 human liver microsomes. ${ }^{20}$ Similarly, fish species, seabirds and ringed seals typically showed 460 enrichment of $E_{1}-\mathrm{PCB} 91 .{ }^{73,74}$ An enrichment of $\mathrm{E}_{2}$-PCB 91 was reported only in a few seabirds 461 and human breastmilk samples. ${ }^{75}$ Unlike PCB 91, the direction of the atropisomeric enrichment 
462 of several toxicologically relevant PCB congeners, in particular, PCB 95 and PCB 136, is

463 different in mice compared to other mammalian species. For example, in vitro, and in vivo

464 studies demonstrate that (-)-PCB 136 is more rapidly eliminated in mice. In contrast, (+)-PCB

465136 is more rapidly metabolized in other mammalian species, resulting in an enrichment of (-)466 PCB $136 .^{1}$

467 The enrichment of PCB 91 in this study was genotype-dependent, with a more 468 pronounced atropisomeric enrichment observed in WT compared to KO mice. This difference in 469 the atropisomeric enrichment is consistent in the slower metabolism of PCB 91 in KO compared 470 to WT mice. In contrast, we did not observe significant differences in the EF values in tissues 471 from KO and WT mice is our earlier disposition studies with PCB 136 at 48 and $72 \mathrm{~h}$ time 472 points, ${ }^{25,43}$ an observation that further highlights the congener-specific differences in the 473 disposition of PCBs (i.e., PCB 91 vs. PCB 136) in KO mice discussed above. The higher fat 474 content in the liver of KO mice does not directly contribute to different EF values in WT 475 compare to KO mice because the partitioning of PCB into fatty tissues is a physicochemical 476 process that is not atropselective. However, the storage of a significant percentage of the total 477 dose of PCB 91 in the liver of KO mice will distribute the PCB away from the site of metabolism 478 and contribute to a reduced elimination of PCB 91, which in turn will influence the atropisomeric 479 enrichment of PCB 91 in target tissues and affect toxic outcomes.

480 The two major PCB 91 metabolites, 5-91 and 4-91, were formed with significant 481 atropisomeric enrichment in KO and WT mice. Typically, the $\mathrm{E}_{1}$-atropisomers of 5-91 and 4-91 482 displayed enrichment in the compartments investigated, irrespective of the genotype. The 483 enrichment of $E_{2}-5-91$ in day 1 feces samples from WT mice and day 1 and day 2 feces samples 484 from $\mathrm{KO}$ was a notable exception. In contrast, $\mathrm{E}_{2}-5-91$ and $\mathrm{E}_{2}-4-91$ are preferentially formed in 
485

486

487

488

489

490

491

492

493

494

495

496 497 hypothesis.

498

499

500

501

502

503

504

505

506

507

studies with mouse liver tissue slices. ${ }^{40}$ These findings demonstrate that in vitro metabolism studies do not necessarily predict the atropisomeric enrichment of OH-PCB in vivo. This observation is not entirely surprising because in vitro models do not recapitulate the complex metabolism and transport processes present in vivo, including the metabolism of PCB metabolites by the intestinal microbiome. It is likely that further metabolism of OH-PCBs to the corresponding sulfates and glucuronides as well as the transport of these PCB metabolites is atropselective, thus resulting in complex chiral mixtures of the OH-PCBs. Consistent with this interpretation of our results; we observed the presence of conjugated PCB 91 metabolites in urine. Moreover, the altered direction of the enrichment of the atropisomers of 5-91 in day 1 compared to day 2 and day 3 samples in WT mice could be due to the atropselective phase II metabolism or transport of OH-PCB 91 metabolites. Further studies of the atropselective metabolism of $\mathrm{OH}-\mathrm{PCBs}$ to sulfate, glucuronide and other conjugates are needed to confirm this

Overall, our study demonstrates differences in the atropselective disposition of PCB 91 and its hydroxylated metabolites in KO compared to WT mice. Moreover, there are congenerspecific difference in the disposition of PCB 91 compared to our earlier study with PCB 136. These differences in the disposition of PCB and their metabolites are not only due to the impaired hepatic metabolism of PCBs caused by the lack of cpr expression in the liver, but also the accumulation of the parent PCB in the liver. Because the deletion of $c p r$ in the liver does not appear to alter the neurodevelopment in KO compared to WT mice, KO mice are a model that could be used to study how an altered disposition of chiral PCBs and OH-PCBs affects neurotoxic outcomes. However, it will be challenging to determine how impaired PCB metabolism vs. PCB sequestration in the fatty liver contribute to toxic outcomes. Moreover, there 
508 are significant differences in the atropselective metabolism of PCBs in mice and humans. ${ }^{19}$

509 Humanized mouse models, such as mice expressing human CYP2B6 enzymes in the liver, ${ }^{76}$ are

510 alternatives for studies of the role of PCB metabolism in PCB-induced developmental

511 neurotoxicity and other adverse outcomes associated with exposure to PCBs.

512

513 FUNDING SOURCES

514 This work was supported by grants ES027169, ES013661, and ES005605 from the

515 National Institute of Environmental Health Sciences, National Institutes of Health. The content is

516 solely the responsibility of the authors and does not necessarily represent the official views of the

517 National Institute of Environmental Health Sciences or the National Institutes of Health.

\section{ACKNOWLEDGMENTS}

520 The authors thank Dr. Xinxin Ding of the Wadsworth Center, New York State

521 Department of Health, for providing the mouse model, Dr. E. Davis Oldham for help with the

522 animal work, Austin Kammerer for help with the PCB analysis, Dr. Kai Wang for advice

523 regarding the statistical analysis, and Dr. Izabela Kania-Korwel for technical support and a

524 critical review of the manuscript.

525

526 SUPPORTING INFORMATION AVAILABLE

527 The supporting information includes a characterization of the mouse model, including 528 body and organ weights; wet weight and lipid-adjusted concentrations of PCB 91 and its 529 metabolites; amount of PCB 91 and it metabolites expressed as percent of the total PCB 91 dose; 530 comparison of the enantiomeric fraction (EF) of the PCB 91, 5-91 and 4-91; limits of detection 531 (LODs) and background levels of PCB 91 and its metabolites; and extractable lipid content in 
532 tissues and excreta WT and KO mice. This material is available free of charge via the Internet at 533 http://pubs.acs.org. 
535 1. Kania-Korwel, I.; Lehmler, H. J., Chiral polychlorinated biphenyls: absorption, 536 metabolism and excretion-a review. Environ. Sci. Pollut. Res. Int. 2016, 23, 2042-2057.

537 2. Hu, D.; Hornbuckle, K. C., Inadvertent polychlorinated biphenyls in commercial paint 538 pigments. Environ. Sci. Technol. 2010, 44, 2822-2827.

539 3. Anezaki, K.; Nakano, T., Concentration levels and congener profiles of polychlorinated biphenyls, pentachlorobenzene, and hexachlorobenzene in commercial pigments. Environ. Sci. Poll. Res. 2013, 21, 1-12.

542 4. Herkert, N. J.; Jahnke, J. C.; Hornbuckle, K. C., Emissions of tetrachlorobiphenyls (PCBs 47, 51, and 68) from polymer resin on kitchen cabinets as a non-Aroclor source to

5. Grimm, F. A.; Hu, D.; Kania-Korwel, I.; Lehmler, H. J.; Ludewig, G.; Hornbuckle, K. C.; Duffel, M. W.; Bergman, A.; Robertson, L. W., Metabolism and metabolites of polychlorinated biphenyls. Crit. Rev. Toxicol. 2015, 45, 245-272.

6. Dhakal, K.; Gadupudi, G. S.; Lehmler, H. J.; Ludewig, G.; Duffel, M. W.; Robertson, L. W., Sources and toxicities of phenolic polychlorinated biphenyls (OH-PCBs). Environ. Sci. Pollut. Res. Int. 2018, 25, 16277-16290.

551 7. ATSDR Toxicological Profile for Polychlorinated Biphenyls (PCBs). https://www.atsdr.cdc.gov/toxprofiles/tp.asp?id=142\&tid=26 (accessed June 3, 2019).

8. Holland, E. B.; Feng, W.; Zheng, J.; Dong, Y.; Li, X.; Lehmler, H.-J.; Pessah, I. N., An extended structure-activity relationship of non-dioxin-like PCBs evaluates and supports modeling predictions and identifies picomolar potency of PCB 202 towards ryanodine receptors. Toxicol. Sci. 2016, 155, 170-181. 
557 9. Niknam, Y.; Feng, W.; Cherednichenko, G.; Dong, Y.; Joshi, S. N.; Vyas, S. M.;

558 Lehmler, H.-J.; Pessah, I. N., Structure-activity relationship of select meta- and para559 hydroxylated non-dioxin-like polychlorinated biphenyls: from single RyR1 channels to 560 muscle dysfunction. Toxicol. Sci. 2013, 136, 500-513.

561 10. Pessah, I. N.; Cherednichenko, G.; Lein, P. J., Minding the calcium store: Ryanodine receptor activation as a convergent mechanism of PCB toxicity. Pharmacol. Ther. 2010, 125, 260-285.

564 11. Pessah, I. N.; Lein, P. J.; Seegal, R. F.; Sagiv, S. K., Neurotoxicity of polychlorinated biphenyls and related organohalogens. Acta Neuropathol. 2019, doi: 10.1007/s0040100019-01978-00401.

567 12. Fonnum, F.; Mariussen, E., Mechanisms involved in the neurotoxic effects of 568

13. Sethi, S.; Morgan, R. K.; Peng, W.; Lin, Y. P.; Li, X. S.; Luna, C.; Koch, M.; Bansal, R.;

14. Pessah, I. N.; Hansen, L. G.; Albertson, T. E.; Garner, C. E.; Ta, T. A.; Do, Z.; Kim, K. H.; Wong, P. W., Structure-activity relationship for noncoplanar polychlorinated biphenyl congeners toward the ryanodine receptor- $\mathrm{Ca}^{2+}$ channel complex type 1 (RyR1). Chem. Res. Toxicol. 2006, 19, 92-101. 
579 15. Kania-Korwel, I.; Lukasiewicz, T.; Barnhart, C. D.; Stamou, M.; Chung, H.; Kelly, K. $580 \quad$ M.; Bandiera, S.; Lein, P. J.; Lehmler, H.-J., Congener-specific disposition of chiral polychlorinated biphenyls in lactating mice and their offspring: Implications for PCB

16. Meerts, I. A.; Assink, Y.; Cenijn, P. H.; Van Den Berg, J. H.; Weijers, B. M.; Bergman,

18. Meerts, I. A. T. M.; Lilienthal, H.; Hoving, S.; van den Berg, J. H. J.; Weijers, B. M.;

17. Lesmana, R.; Shimokawa, N.; Takatsuru, Y.; Iwasaki, T.; Koibuchi, N., Lactational exposure to hydroxylated polychlorinated biphenyl (OH-PCB 106) causes hyperactivity in male rat pups by aberrant increase in dopamine and its receptor. Environ. Toxicol. 2014, 29, 876-883.

601 Bergman, A.; Koeman, J. H.; Brouwer, A., Developmental exposure to 4-hydroxy-2,3,3 ',4 ',5-pentachlorobiphenyl (4-OH-CB107): Long-term effects on brain development, behavior, and brain stem auditory evoked potentials in rats. Toxicol. Sci. 2004, 82, 207218.

19. Uwimana, E.; Ruiz, P.; Li, X.; Lehmler, H. J., Human CYP2A6, CYP2B6, and CYP2E1 atropselectively metabolize polychlorinated biphenyls to hydroxylated metabolites. Environ. Sci. Technol. 2019, 53, 2114-2123.

20. Uwimana, E.; Li, X.; Lehmler, H.-J., Human liver microsomes atropselectively metabolize 2,2',3,4',6-pentachlorobiphenyl (PCB 91) to a 1,2-shift product as the major metabolite. Environ. Sci. Technol. 2018, 52, 6000-6008. 
602 21. Uwimana, E.; Li, X.; Lehmler, H.-J., 2,2',3,5',6-Pentachlorobiphenyl (PCB 95) is 603 atropselectively metabolized to para-hydroxylated metabolites by human liver 604 microsomes. Chem. Res. Toxicol. 2016, 29, 2108-2110.

605 22. Wu, X.; Kammerer, A.; Lehmler, H. J., Microsomal oxidation of 2,2',3,3',6,6'606 hexachlorobiphenyl (PCB 136) results in species-dependent chiral signatures of the 607 hydroxylated metabolites. Environ. Sci. Technol. 2014, 48, 2436-2444.

608 23. Schnellmann, R. G.; Putnam, C. W.; Sipes, I. G., Metabolism of 2,2',3,3',6,6'609 hexachlorobiphenyl and 2,2',4,4',5,5'-hexachlorobiphenyl by human hepatic microsomes. $610 \quad$ Biochem. Pharmacol. 1983, 32, 3233-3239.

$61124 . \quad$ Lehmler, H. J., Synthesis of environmentally relevant fluorinated surfactants--a review. $612 \quad$ Chemosphere 2005, 58, 1471-1496.

613 25. Wu, X.; Barnhart, C.; Lein, P. J.; Lehmler, H. J., Hepatic metabolism affects the 614 atropselective disposition of 2,2',3,3',6,6'-hexachlorobiphenyl (PCB 136) in mice. $615 \quad$ Environ. Sci. Technol. 2015, 49, 616-625.

616 26. Lehmler, H.-J.; Harrad, S. J.; Huhnerfuss, H.; Kania-Korwel, I.; Lee, C. M.; Lu, Z.; 617 Wong, C. S., Chiral polychlorinated biphenyl transport, metabolism, and distribution: A 618 review. Environ. Sci. Technol. 2010, 44, 2757-2766.

619 27. Pessah, I. N.; Lehmler, H.-J.; Robertson, L. W.; Perez, C. F.; Cabrales, E.; Bose, D. D.; 620 Feng, W., Enantiomeric specificity of (-)-2,2',3,3',6,6'-hexachlorobiphenyl toward 621 ryanodine receptor types 1 and 2. Chem. Res. Toxicol. 2009, 22, 201-207.

622 28. Feng, W.; Zheng, J.; Robin, G.; Dong, Y.; Ichikawa, M.; Inoue, Y.; Mori, T.; Nakano, T.; 623 Pessah, I. N., Enantioselectivity of 2,2',3,5',6-pentachlorobiphenyl (PCB 95) atropisomers 
toward ryanodine receptors (RyRs) and their influences on hippocampal neuronal networks. Environ. Sci. Technol. 2017, 51, 14406-14416.

626 29. Yang, D.; Kania-Korwel, I.; Ghogha, A.; Chen, H.; Stamou, M.; Bose, D. D.; Pessah, I. 627 N.; Lehmler, H. J.; Lein, P. J., PCB 136 atropselectively alters morphometric and functional parameters of neuronal connectivity in cultured rat hippocampal neurons via ryanodine receptor-dependent mechanisms. Toxicol. Sci. 2014, 138, 379-392.

630 30. Gu, J.; Weng, Y.; Zhang, Q. Y.; Cui, H.; Behr, M.; Wu, L.; Yang, W.; Zhang, L.; Ding, X., Liver-specific deletion of the NADPH-cytochrome P450 reductase gene: impact on plasma cholesterol homeostasis and the function and regulation of microsomal cytochrome P450 and heme oxygenase. J. Biol. Chem. 2003, 278, 25895-25901.

634 31. Wu, L.; Gu, J.; Weng, Y.; Kluetzman, K.; Swiatek, P.; Behr, M.; Zhang, Q. Y.; Zhuo, X.; Xie, Q.; Ding, X., Conditional knockout of the mouse NADPH-cytochrome P450 reductase gene. Genesis 2003, 36, 177-181.

637 32. Joshi, S. N.; Vyas, S. M.; Duffel, M. W.; Parkin, S.; Lehmler, H.-J., Synthesis of

33. Kania-Korwel, I.; Shaikh, N. S.; Hornbuckle, K. C.; Robertson, L. W.; Lehmler, H.-J., Enantioselective disposition of PCB 136 (2,2',3,3',6,6'-hexachlorobiphenyl) in C57BL/6 mice after oral and intraperitoneal administration. Chirality 2007, 19, 56-66.

642 34. Kania-Korwel, I.; Hornbuckle, K. C.; Robertson, L. W.; Lehmler, H.-J., Dose-dependent enantiomeric enrichment of 2,2',3,3',6,6'-hexachlorobiphenyl in female mice. Environ. Toxicol. Chem. 2008, 27, 299-305. 
645 35. Kania-Korwel, I.; Hornbuckle, K. C.; Robertson, L. W.; Lehmler, H.-J., Influence of dietary fat on the enantioselective disposition of 2,2',3,3',6,6'-hexachlorobiphenyl (PCB 136) in female mice. Food Chem. Toxicol. 2008, 46, 637-644.

648 36. Kania-Korwel, I.; Xie, W.; Hornbuckle, K. C.; Robertson, L. W.; Lehmler, H.-J., Enantiomeric enrichment of 2,2',3,3',6,6'-hexachlorobiphenyl (PCB 136) in mice after

37. Kania-Korwel, I.; Barnhart, C. D.; Stamou, M.; Truong, K. M.; El-Komy, M. H.; Lein, P. J.; Veng-Pedersen, P.; Lehmler, H.-J., 2,2',3,5',6-Pentachlorobiphenyl (PCB 95) and its hydroxylated metabolites are enantiomerically enriched in female mice. Environ. Sci. Technol. 2012, 46, 11393-11401.

38. Kania-Korwel, I.; Zhao, H.; Norstrom, K.; Li, X.; Hornbuckle, K. C.; Lehmler, H.-J., Simultaneous extraction and clean-up of PCBs and their metabolites from small tissue samples using pressurized liquid extraction. J. Chromatogr. A 2008, 1214, 37-46.

39. Wu, X.; Kania-Korwel, I.; Chen, H.; Stamou, M.; Dammanahalli, K. J.; Duffel, M.; Lein, atropisomers in tissue slices from phenobarbital or dexamethasone-induced rats is sexdependent. Xenobiotica 2013, 43, 933-947.

40. Wu, X.; Duffel, M.; Lehmler, H.-J., Oxidation of polychlorinated biphenyls by liver 663 tissue slices from phenobarbital-pretreated mice is congener-specific and atropselective. Chem. Res. Toxicol. 2013, 26, 1642-1651.

665 41. Kania-Korwel, I.; Lehmler, H.-J., Assigning atropisomer elution orders using 666 atropisomerically enriched polychlorinated biphenyl fractions generated by microsomal metabolism. J. Chromatogr. A 2013, 1278, 133-144. 
668 42. R Core Team (2013). R: A language and environment for statistical computing. R 669 Foundation for Statistical Computing, Vienna, Austria. URL http://www.R-project.org/ (accessed June 3, 2019).

671 43. Li, X.; Wu, X.; Kelly, K. M.; Veng-Pedersen, P.; Lehmler, H.-J., Toxicokinetics of chiral PCB 136 and its hydroxylated metabolites in mice with a liver-specific deletion of cytochrome P450 reductase. Chem. Res. Toxicol. 2019, 32, 727-736.

44. $\quad$ Gu, J.; Cui, H.; Behr, M.; Zhang, L.; Zhang, Q.-Y.; Yang, W.; Hinson, J. A.; Ding, X., In and nasal mucosa. Mol. Pharmacol. 2005, 67, 623-630.

678 45. Wu, L.; Gu, J.; Cui, H.; Zhang, Q. Y.; Behr, M.; Fang, C.; Weng, Y.; Kluetzman, K.; Swiatek, P. J.; Yang, W.; Kaminsky, L.; Ding, X., Transgenic mice with a hypomorphic NADPH-cytochrome P450 reductase gene: effects on development, reproduction, and microsomal cytochrome P450. J. Pharmacol. Exp. Ther. 2005, 312, 35-43.

46. Van Birgelen, A. P. J. M.; Van der Kolk, J.; Fase, K. M.; Bol, I.; Poiger, H.; Brouwer, A.; Van den Berg, M., Toxic potency of 3,3',4,4',5-pentachlorobiphenyl relative to and in combination with 2,3,7,8-tetrachlorodibenzo-p-dioxin in a subchronic feeding study in the rat. Toxicol. Appl. Pharmacol. 1994, 127, 209-221.

47. Chu, I.; Villeneuve, D. C.; Yagminas, A.; Lecavalier, P.; Poon, R.; Feeley, M.; Kennedy, 3,3',4,4',5-pentachlorobiphenyl in the rat. 1. Clinical, biochemical, hematological, and histopathological changes. Fundam. Appl. Toxicol. 1994, 22, 457-468. 
690

691

692

693

694

695

696

697

698

699

700

701

702

703

704

705

706

707

708

709

710

711

48. Cichocki, J. A.; Furuya, S.; Konganti, K.; Luo, Y.-S.; McDonald, T. J.; Iwata, Y.; Chiu, W. A.; Threadgill, D. W.; Pogribny, I. P.; Rusyn, I., Impact of Nonalcoholic fatty liver disease on toxicokinetics of tetrachloroethylene in mice. J. Pharmacol. Exp. Ther. 2017, $361,17-28$.

49. Kania-Korwel, I.; Hrycay, E. G.; Bandiera, S. M.; Lehmler, H.-J., 2,2',3,3',6,6'Hexachlorobiphenyl (PCB 136) atropisomers interact enantioselectively with hepatic microsomal cytochrome P450 enzymes. Chem. Res. Toxicol. 2008, 21, 1295-1303.

50. Chen, J. J.; Chen, G. S.; Bunce, N. J., Inhibition of CYP 1A2-dependent MROD activity in rat liver microsomes: An explanation of the hepatic sequestration of a limited subset of halogenated aromatic hydrocarbons. Environ. Toxicol. 2003, 18, 115-119.

51. Diliberto, J. J.; Burgin, D. E.; Birnbaum, L. S., Effects of CYP1A2 on disposition of 2,3,7,8-tetrachlorodibenzo-p-dioxin, 2,3,4,7,8-pentachlorodibenzofuran, and 2,2',4,4',5,5'hexachlorobiphenyl in CYP1A2 knockout and parental (C57BL/6N and 129/Sv) strains of mice. Toxicol. Appl. Pharmacol. 1999, 159, 52-64.

52. Birnbaum, L. S., Distribution and excretion of 2,3,6,2',3',6'- and 2,4,5,2',4',5'hexachlorobiphenyl in senescent rats. Toxicol. Appl. Pharmacol. 1983, 70, 262-272.

53. Milanowski, B.; Lulek, J.; Lehmler, H.-J.; Kania-Korwel, I., Assessment of the disposition of chiral polychlorinated biphenyls in female mdr 1a/b knockout versus wildtype mice using multivariate analyses. Environ. Int. 2010, 36, 884-892.

54. Weng, Y.; DiRusso, C. C.; Reilly, A. A.; Black, P. N.; Ding, X., Hepatic gene expression changes in mouse models with liver-specific deletion or global suppression of the NADPH-cytochrome P450 reductase gene. Mechanistic implications for the regulation of 
microsomal cytochrome P450 and the fatty liver phenotype. J. Biol. Chem. 2005, 280, 31686-31698.

714 55. Gobas, F. A. P. C.; Muir, D. C. G.; Mackay, D., Dynamics of dietary bioaccumulation and fecal elimination of hydrophobic organic chemicals in fish. Chemosphere 1988, 17, 943-962.

717 56. Redgrave, T. G.; Wallace, P.; Jandacek, R. J.; Tso, P., Treatment with a dietary fat substitute decreased Arochlor 1254 contamination in an obese diabetic male. J. Nutr. Biochem. 2005, 16, 383-384.

720 57. Wahlang, B.; Falkner, K. C.; Clair, H. B.; Al-Eryani, L.; Prough, R. A.; States, J. C.;

58. Younossi, Z.; Anstee, Q. M.; Marietti, M.; Hardy, T.; Henry, L.; Eslam, M.; George, J.;

Bugianesi, E., Global burden of NAFLD and NASH: trends, predictions, risk factors and prevention. Nat. Rev. Gastroenterol. Hepatol. 2017, 15, 11-20.

726

727

728

729

730

731

732

733 1260, a polychlorinated biphenyl mixture. Toxicol. Sci. 2014, 140, 283-297.

59. Kania-Korwel, I.; Barnhart, C. D.; Lein, P. J.; Lehmler, H.-J., Effect of pregnancy on the disposition of 2,2',3,5',6-pentachlorobiphenyl (PCB 95) atropisomers and their hydroxylated metabolites in female mice. Chem. Res. Toxicol. 2015, 28, 1774-1783.

60. Kunisue, T.; Sakiyama, T.; Yamada, T. K.; Takahashi, S.; Tanabe, S., Occurrence of hydroxylated polychlorinated biphenyls in the brain of cetaceans stranded along the Japanese coast. Mar. Pollut. Bull. 2007, 54, 963-973.

61. Gebbink, W. A.; Sonne, C.; Dietz, R.; Kirkegaard, M.; Riget, F. F.; Born, E. W.; Muir, D. C.; Letcher, R. J., Tissue-specific congener composition of organohalogen and metabolite 
contaminants in East Greenland polar bears (Ursus maritimus). Environ. Pollut. 2008, 152, 621-629.

62. Dhakal, K.; Uwimana, E.; Adamcakova-Dodd, A.; Thorne, P. S.; Lehmler, H. J.; Robertson, L. W., Disposition of phenolic and sulfated metabolites after inhalation exposure to 4-chlorobiphenyl (PCB3) in female rats. Chem. Res. Toxicol. 2014, 27, 14111420.

740 63. Dhakal, K.; Adamcakova-Dodd, A.; Lehmler, H. J.; Thorne, P. S.; Robertson, L. W., (PCB3). Chem. Res. Toxicol. 2013, 26, 853-855.

743 64. Hu, X.; Adamcakova-Dodd, A.; Thorne, P. S., The fate of inhaled ${ }^{14}$ C-labeled PCB11 and its metabolites in vivo. Environ. Int. 2014, 63, 92-100.

745 65. Lucier, G. W.; McDaniel, O. S.; Schiller, C. M.; Matthews, H. B., Structural requirements for the accumulation of chlorinated biphenyl metabolites in the fetal rat intestine. Drug Metab. Dispos. 1978, 6, 584-590.

66. Grimm, F. A.; Lehmler, H. J.; Koh, W. X.; DeWall, J.; Teesch, L. M.; Hornbuckle, K. C.; Thorne, P. S.; Robertson, L. W.; Duffel, M. W., Identification of a sulfate metabolite of PCB 11 in human serum. Environ. Int. 2017, 98, 120-128.

751 67. Dhakal, K.; He, X.; Lehmler, H.-J.; Teesch, L. M.; Duffel, M. W.; Robertson, L. W., 752 Identification of sulfated metabolites of 4-chlorobiphenyl (PCB3) in the serum and urine of male rats. Chem. Res. Toxicol. 2012, 25, 2796-2804.

754 68. Liu, Y.; Richardson, E. S.; Derocher, A. E.; Lunn, N. J.; Lehmler, H. J.; Li, X.; Zhang, 755 Y.; Cui, J. Y.; Cheng, L.; Martin, J. W., Hundreds of unrecognized halogenated 
contaminants discovered in polar bear serum. Angew. Chem. Int. Ed. Engl. 2018, 57, $757 \quad 16401-16406$.

758 69. He, Z.; Wang, Y.; Zhang, Y.; Cheng, H.; Liu, X., Stereoselective bioaccumulation of 759 chiral PCB 91 in earthworm and its metabolomic and lipidomic responses. Environ. Poll. $760 \quad$ 2018, 238, 421-430.

761 70. Kania-Korwel, I.; El-Komy, M. H. M. E.; Veng-Pedersen, P.; Lehmler, H.-J., Clearance 762 of polychlorinated biphenyl atropisomers is enantioselective in female C57Bl/6 mice. 763 Environ. Sci. Technol. 2010, 44, 2828-2835.

764 71. Kania-Korwel, I.; Duffel, M. W.; Lehmler, H.-J., Gas chromatographic analysis with 765 chiral cyclodextrin phases reveals the enantioselective formation of hydroxylated 766 polychlorinated biphenyls by rat liver microsomes. Environ. Sci. Technol. 2011, 45, $767 \quad 9590-9596$.

768 72. Lu, Z.; Kania-Korwel, I.; Lehmler, H. J.; Wong, C. S., Stereoselective formation of 769 mono- and dihydroxylated polychlorinated biphenyls by rat cytochrome P450 2 B1. 770 Environ. Sci. Technol. 2013, 47, 12184-12192.

$771 \quad$ 73. Wong, C. S.; Mabury, S. A.; Whittle, D. M.; Backus, S. M.; Teixeira, C.; DeVault, D. S.; 772 Bronte, C. R.; Muir, D. C. G., Organochlorine compounds in Lake Superior: Chiral 773 polychlorinated biphenyls and biotransformation in the aquatic food web. Environ. Sci. 774 Technol. 2004, 38, 84-92.

775 74. Warner, N. A.; Norstrom, R. J.; Wong, C. S.; Fisk, A. T., Enantiomeric fractions of chiral 776 polychlorinated biphenyls provide insights on biotransformation capacity of arctic biota. 777 Environ. Toxicol. Chem. 2005, 24, 2763-2767. 
778 75. Bordajandi, L. R.; Abad, E.; Gonzalez, M. J., Occurrence of PCBs, PCDD/Fs, PBDEs 779 and DDTs in Spanish breast milk: Enantiomeric fraction of chiral PCBs. Chemosphere $780 \quad 2008,70,567-575$.

781 76. Zhang, Q. Y.; Gu, J.; Su, T.; Cui, H.; Zhang, X. L.; D'Agostino, J.; Zhuo, X. L.; Yang, 782 W. Z.; Swiatek, P. J.; Ding, X. X., Generation and characterization of a transgenic mouse 783 model with hepatic expression of human CYP2A6. Biochem. Biophys. Res. Commun. $784 \quad 2005,338,318-324$. 


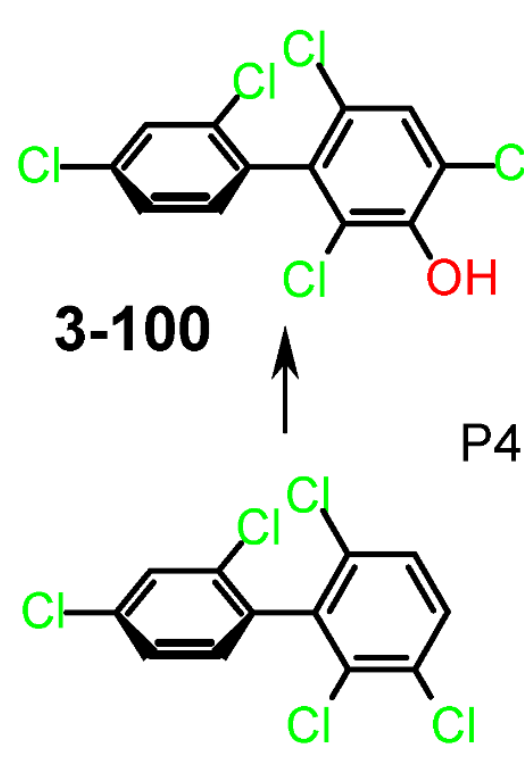

PCB 91

\section{OH-PCB 91 glucuronide}

UGT

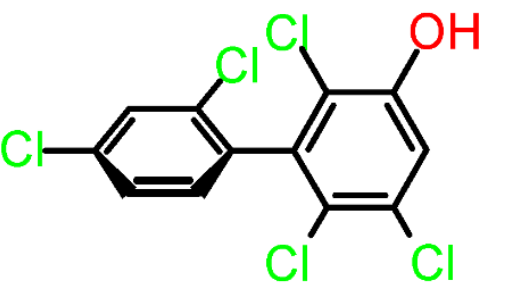

5-91

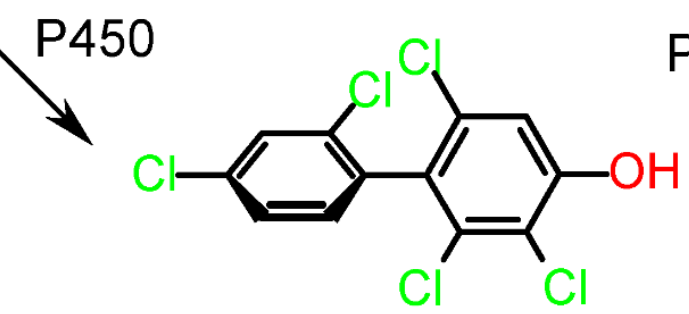

\section{$\mathrm{P} 450$}

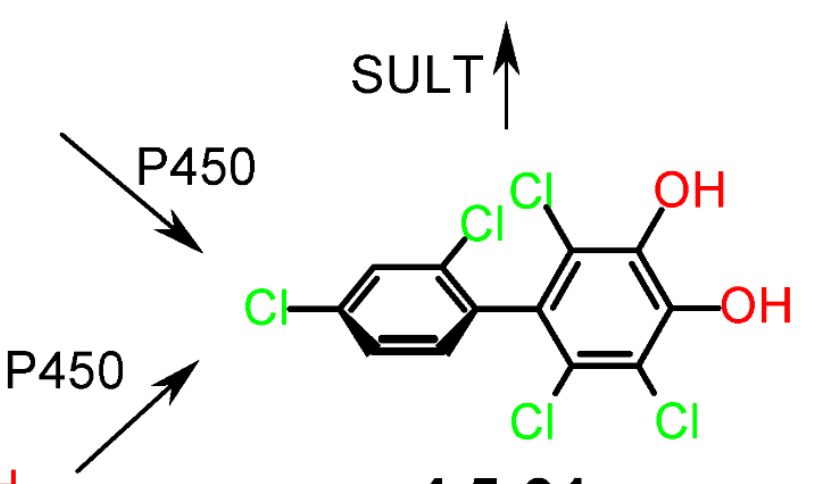

diOH-PCB 91 sulfate

4.5-91

4-91

Figure 1: Simplified metabolism scheme of PCB 91. Only one atropisomer of PCB 91 and its metabolites are shown for clarity reasons. 


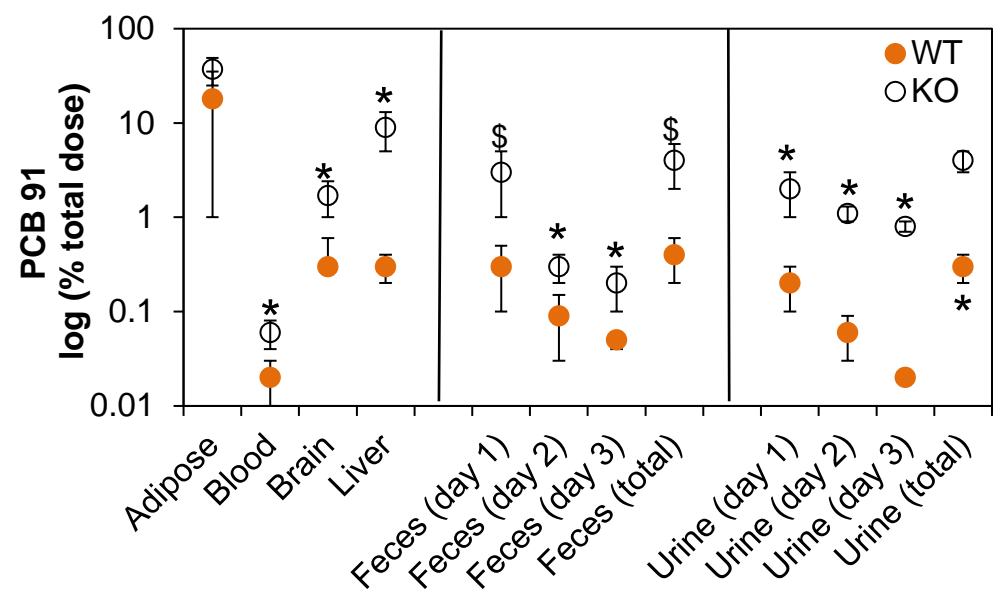

Figure 2. Mice with a liver-specific deletion of the cpr gene (KO mice) have significantly higher levels of PCB 91 compared to the corresponding congenic wild type mice (WT mice). PCB 91 levels are expressed on a logarithmic scale as a percent of the total PCB 91 dose (see Table S6 for additional details). *Significantly different from WT $(\mathrm{p}<0.05)$ analyzed by Student’s t-test; ${ }^{\$}$ $(0.05 \leq \mathrm{p}<0.1)$ analyzed by Student's t-test; nd, not detected. 

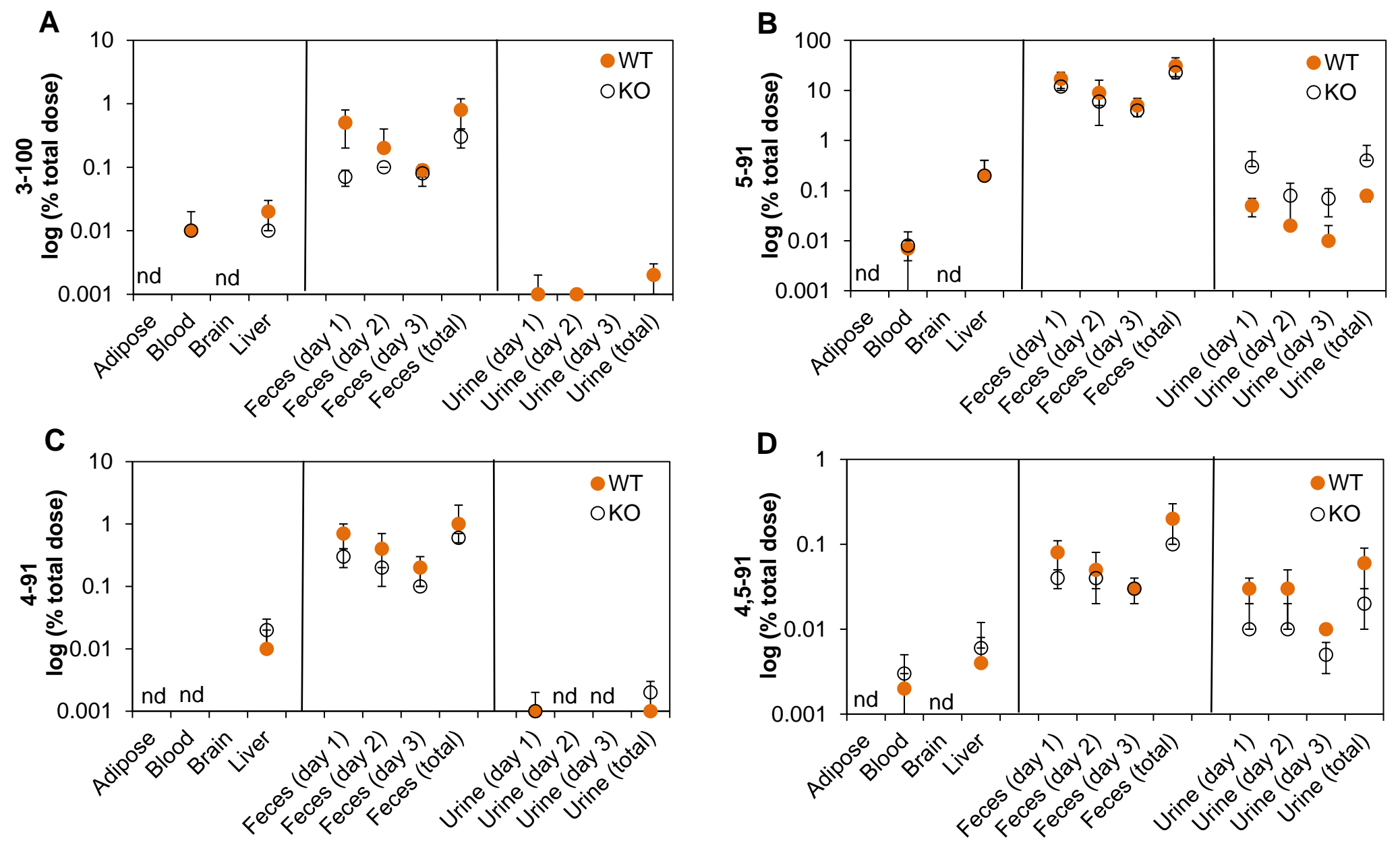

Figure 3. Levels of (A) 3-100, (B) 5-91, (C) 4-91, (D) 4,5-91 in tissues and excreta show little differences between mice with a liverspecific deletion of the cpr gene (KO mice) and the corresponding congenic wild type mice (WT mice). OH-PCB metabolite levels are expressed on a logarithmic scale as a percent of the total PCB 91 dose (see Table S6 for additional details). nd, not detected. 

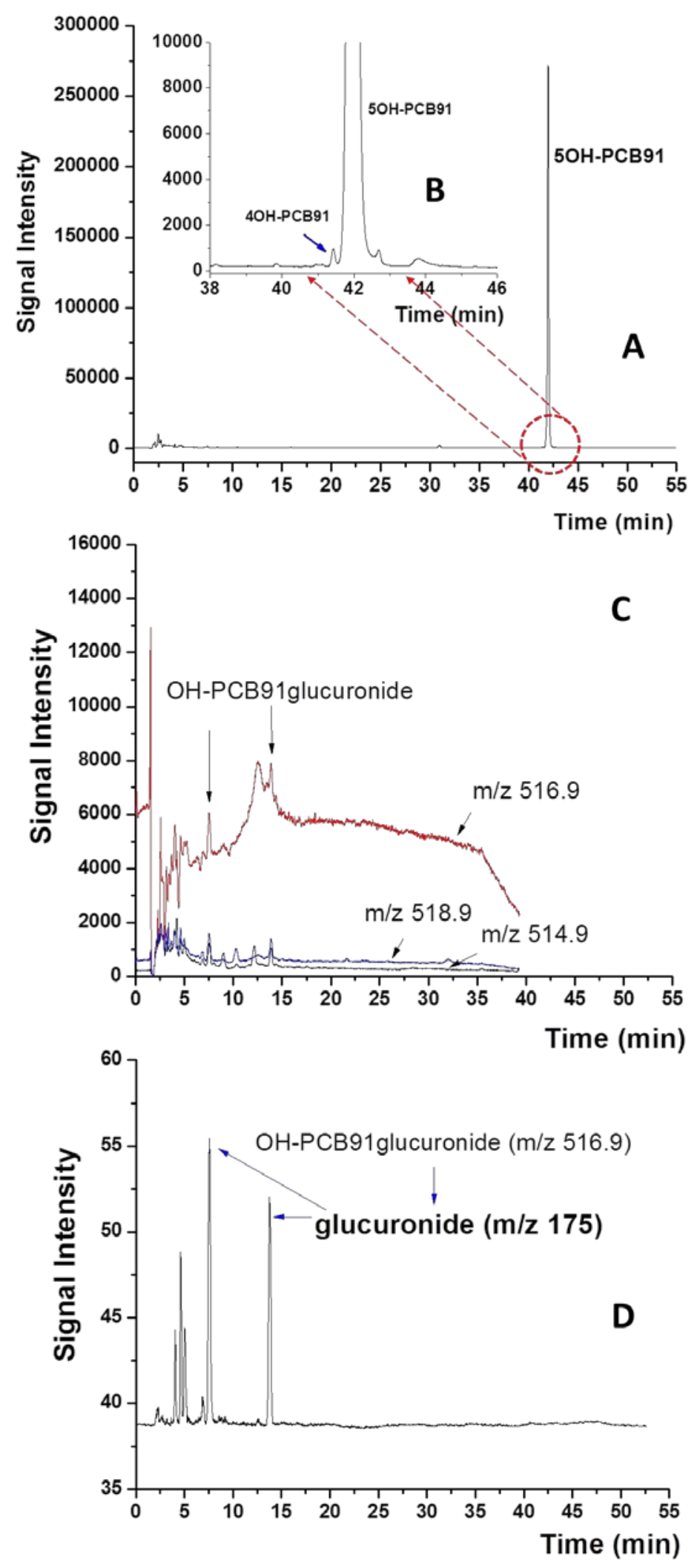

Figure 4: Analysis of a urine sample from a representative mouse dosed with PCB 91 by LC/MS 
demonstrates the presence of PCB 91 metabolites. The presence of (A) 5-91 and (B) 4-91 was confirmed in the scan mode with a mass in the range of 100-800 amu in the negative mode. (C) Analysis in the SIM mode showed two peaks at retention times of 7.5 and $13.9 \mathrm{~min}$. The theoretical isotope ratios $0.617: 1: 0.648$ of $\mathrm{m} / \mathrm{z}$ at $514.9,516.9$, and 518.9 is consistent with the presence of monohydroxylated PCB 91 metabolites present in the urine sample. (D) Further confirmation of monohydroxylated PCB 91 operated by MRM mode with transitions of m/z $516.9>175.0$ showed two peaks with the same retention times. The instrument parameters are described in the Experimental section. 

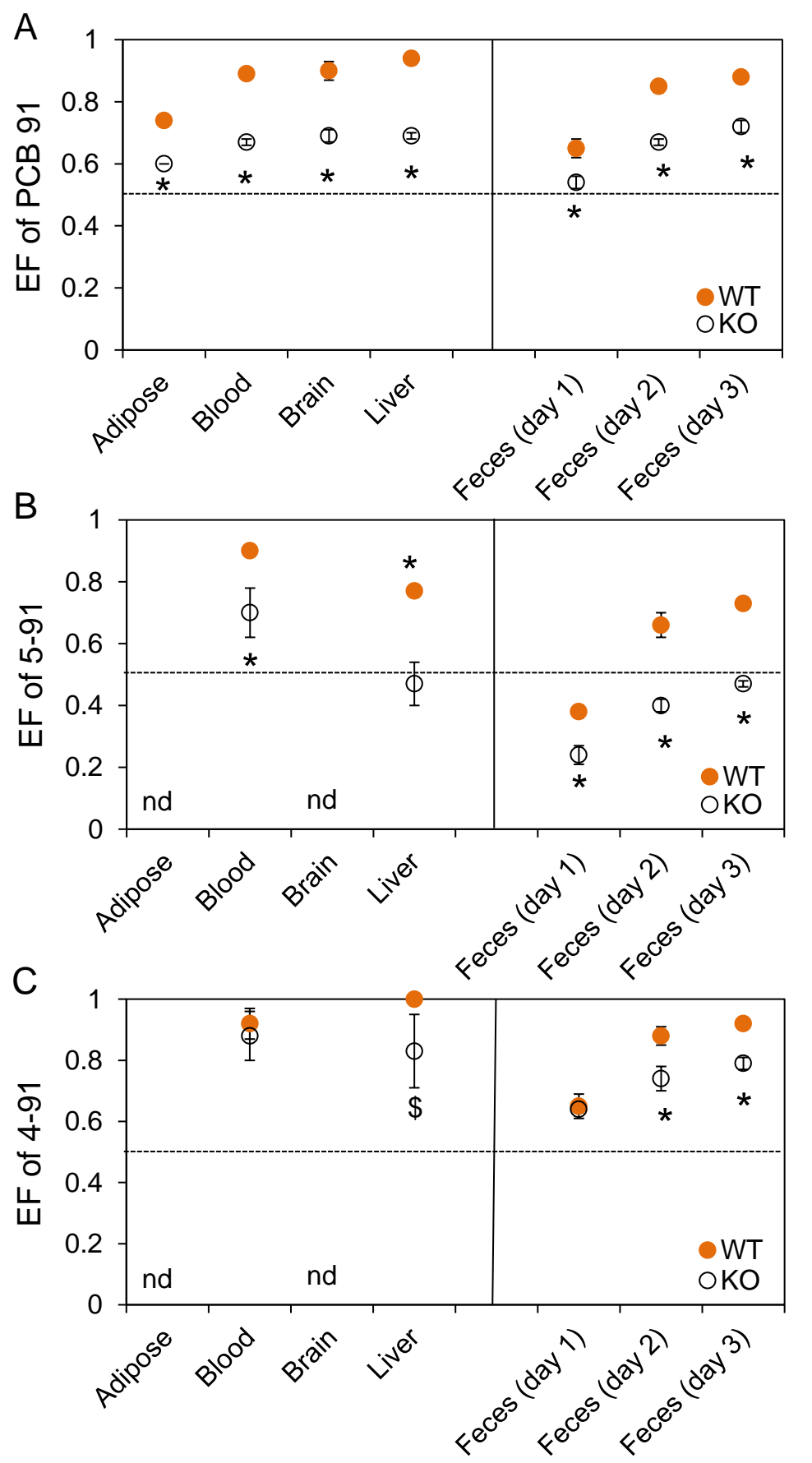

Figure 5. Comparison of the enantiomeric fractions (EFs) of (A) PCB 91, (B) 5-91 and (C) 4-91 in tissues and feces reveals significant differences in the atropisomeric enrichment between KO and WT mice following oral administration of PCB 91. EF values greater than 0.5 represent an enrichment of the first eluting atropisomer $\left(E_{1}\right)$, and $E F$ values less than 0.5 represent an enrichment of the second eluting atropisomer $\left(E_{2}\right)$. Atropselective separations were performed 
on a BDM column as described in the Experimental section. The dotted line indicates the EF values of the respective racemic standard. * Significantly different from WT $(\mathrm{p}<0.05)$ analyzed by Student’s t-test; ${ }^{\$} \mathrm{p}<0.1$ analyzed by Student’s t-test; nd, not detected. 


\title{
SUPPORTING INFORMATION
}

\section{Atropselective Disposition of 2,2',3,4',6-Pentachlorobiphenyl \\ (PCB 91) and Identification of Its Metabolites in Mice with Liver- specific Deletion of Cytochrome P450 Reductase}

\author{
Xianai $\mathrm{Wu}^{\dagger}$, Guangshu Zhai ${ }^{\ddagger \S}$, Jerald L. Schnoor ${ }^{\dagger, \sharp,}$, Hans-Joachim Lehmler ${ }^{\dagger, \S, *}$ \\ ${ }^{\dagger}$ Department of Occupational and Environmental Health; ${ }^{\ddagger}$ Department of Civil and \\ Environmental Engineering; ${ }^{\S}$ IIHR Hydroscience and Engineering, The University of Iowa, Iowa \\ City, IA, 52242, USA
}

Corresponding Author:

Dr. Hans-Joachim Lehmler

The University of Iowa

Department of Occupational and Environmental Health

University of Iowa Research Park, B164 MTF

Iowa City, IA 52242-5000

Phone: (319) 335-4981

Fax: (319) 335-4290 
e-mail: hans-joachim-lehmler@uiowa.edu 


\section{Table of Contents}

Abbreviations $\quad 3$

$\begin{array}{ll}\text { Animals } & 4\end{array}$

Quality assurance/quality control of the GC- $\mu \mathrm{ECD}$ analyses $\quad 4$

Table S1: Body and organ weights of female WT and KO mice (12 13 weeks old) 6 dosed with PCB 91 or vehicle (cookie).

Table S2: Concentrations of PCB 91 (ng/g wet weight) in tissues, blood, and excreta in WT and KO mice after oral administration of PCB 91.

Table S3: Concentrations of OH-PCB 91 metabolites (ng/g wet weight) in tissues blood and excreta in WT and KO mice after oral administration of PCB 91.

Table S4: Lipid adjusted concentrations of PCB 91 ( $\mu \mathrm{g} / \mathrm{g}$ lipid) in tissues and feces in WT and KO mice after oral administration of PCB 91.

Table S5: Concentrations of OH-PCB 91 ( $\mu \mathrm{g} / \mathrm{g}$ lipid) in tissues and feces in WT and KO mice after oral administration of PCB 91.

Table S6: The amount of PCB 91 and OH-PCB 91 metabolites in tissue, blood, and excreta expressed as a percent of total dose in WT and $\mathrm{KO}$ mice after oral administration of PCB 91.

Table S7: Comparison of the enantiomeric fraction (EF) of the PCB 91 and its metabolites, 5-91 and 4-91, in tissues and excreta in WT and KO mice after oral administration of PCB 91.

Table S8: Limits of detection (LODs) and background levels of PCB 91 and its metabolites in tissues from mice dosed with vehicle alone.

Table S9: Limits of detection (LODs) and background levels of PCB 91 and its metabolites in blood and urine from animals dosed with vehicle alone.

Table S10: Extractable lipid content expressed as a percent of tissue or feces wet weight (\%) in PCB 91 or vehicle-treated WT and KO mice.

Figure S1: Increased concentration of 5-91 and 4,5-91 in day 1 urine after $\beta$ glucuronidase/sulfatase treatment.

Figure S2: Increased concentration of 5-91 and 4,5-91 in day 2 urine after $\beta$ glucuronidase/sulfatase treatment.

Figure S3: Increased concentration of 5-91 and 4,5-91 in day 3 urine after $\beta$ glucuronidase/sulfatase treatment. 


\section{Abbreviations:}

3-100, 2,2',4,4',6-pentachlorobiphenyl-3-ol

4'-159, 2,3,3',4,5,5'-hexachlorobiphenyl-4'-ol

4,5-91, 2,2', 3, 4', 6-pentachlorobiphenyl-4,5-diol

4-91, 2,2',3,4',6-pentachlorobiphenyl-4-ol

5-91, 2,2',3,4',6-pentachlorobiphenyl-5-ol

BDM, ChiralDex BDM column

CD, CP-Chirasil-DEX CB

EF, enantiomeric fraction

GC, gas chromatography

$\mathrm{KO}$, mice with liver-specific deletion of the NADPH-cytochrome $\mathrm{P} 450$ reductase gene

$L O D$, limit of detection

OH-PCB 91, hydroxylated PCB 91

$\mu \mathrm{ECD}$, micro electron capture detector

PCB, polychlorinated biphenyl

PCB 117, 2,3,4',5,6-pentachlorobiphenyl

PCB 91, 2,2',3,4',6-pentachlorobiphenyl

$\mathrm{SD}$, standard deviation

WT, wild type mice 
Animals: Dr. Xinxin Ding (School of Public Health, State University of New York, Albany, NY)

provided breeding pairs of Alb-Cre ${ }^{+/} / \mathrm{Cpr}^{\text {lox+/+ }}$ mice with a liver-specific deletion of the cytochrome P450 oxidoreductase gene (KO) and Alb-Cre ${ }^{-/} / \mathrm{Cpr}^{\text {lox+/+ }}$ mice (wild type, WT). ${ }^{2,3}$

Breeding pairs were set up between $\mathrm{KO}$ and WT mice, and littermates were genotyped in the University of Iowa Transgenic Animal Facility following a published protocol. $\stackrel{2}{ }$ Animals were housed in standard plastic cages in a temperature-controlled room $\left(22 \pm 2{ }^{\circ} \mathrm{C}\right)$ with a $12 \mathrm{~h}$ lightdark cycle. Basal diet (Harlan 7913 with 18\% protein, 6\% fat, and 5\% fiber) and water were provided ad libitum..$^{4}$

The relative liver weight was higher, and the relative heart weight was lower in KO compared to WT mice (Table S1), which is consistent with earlier studies in the mouse model. Also, there were no other significant differences in body weights or relative organ weights. ${ }^{14,15}$ As described

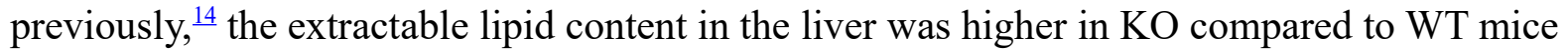
(Table S10), probably due to adaptive changes in the expression of hepatic xenobiotic processing genes. ${ }^{16}$ Besides, the lipid content in feces was higher in $\mathrm{KO}$ compared to WT mice. The higher fecal fat levels are due to the lack of bile acid synthesis, which in turn decreases the absorption of dietary fats from the gastrointestinal tract. ${ }^{14,17}$ PCB exposure did not affect hepatic or fecal lipid levels.

Quality assurance/quality control of the GC- $\mu$ ECD analyses. The ${ }^{63} \mathrm{Ni}-\mu \mathrm{ECD}$ used for the analysis of PCB 91 and its hydroxylated metabolites were linear up to concentrations of 1,000 $\mathrm{ng} / \mathrm{mL}\left(\mathrm{R}^{2}>0.999\right)$. The recoveries of the surrogate recovery standards PCB 117 and 4'-159 were $104 \pm 10 \%$ (range: $83 \%$ to $118 \%$ ) and $95 \pm 8 \%$ (range: $76 \%$ to $105 \%$ ), respectively. The limits of detection and background levels in control animals are summarized in Tables S8 and S9 for 
each matrix. Levels of PCB 91 and its hydroxylated metabolites were adjusted for recoveries if the recovery was less than $100 \%$ for the individual sample. The resolution of PCB 91, 4-91, and 5-91 atropisomers on the ChiralDex BDM (BDM) column (30 m length, $250 \mu \mathrm{m}$ inner diameter, $0.12 \mu \mathrm{m}$ film thickness; Supelco, St. Louis, MO) was $0.971,0.580$ and 1.583 , respectively; the resolution of PCB 91 and 5-91 atropisomers on the CP-ChiraSil-DEX CB (CD) column (30 m length, $250 \mu \mathrm{m}$ inner diameter, $0.12 \mu \mathrm{m}$ film thickness; Agilent Technologies, Santa Clara, CA) was 0.837 and 1.333, respectively. $\frac{13}{}$ The EF values for the racemic standards of PCB 91, 4-91, and 5-91 on the BDM column were $0.498 \pm 0.010,0.493 \pm 0.010$ and $0.495 \pm 0.006$; the $\mathrm{EF}$ values of PCB 91 and 5-91 on the CD column were $0.492 \pm 0.010$ and $0.497 \pm 0.009$. 
Table S1: Body and organ weights of female WT and KO mice (12 13 weeks old) dosed with PCB 91 or vehicle (cookie). ${ }^{\$}$

\begin{tabular}{|c|c|c|c|c|c|c|c|c|c|c|c|c|c|c|c|}
\hline \multirow{2}{*}{ Dose } & \multirow{2}{*}{$\begin{array}{l}\text { Mouse } \\
\text { strain }\end{array}$} & \multicolumn{2}{|c|}{ Body weight [g] } & \multicolumn{6}{|c|}{ Organ weight $[\mathrm{g}]$} & \multicolumn{6}{|c|}{$\underline{\text { Organ adjusted by b.w. [\%] }}]^{\star}$} \\
\hline & & Initial & final & Brain & Heart & Kidney & Liver & Lung & Spleen & Brain & Heart & Kidney & Liver & Lung & Spleen \\
\hline \multirow{2}{*}{ Vehicle } & WT $(n=2)$ & $\begin{array}{c}25.9 \pm 3 . \\
5\end{array}$ & $\begin{array}{c}23.3 \pm 1 . \\
2\end{array}$ & $\begin{array}{c}0.41 \pm 0.0 \\
5\end{array}$ & $\begin{array}{c}0.13 \pm 0.0 \\
0\end{array}$ & $0.25 \pm 0.08$ & $\begin{array}{c}1.08 \pm 0.0 \\
9\end{array}$ & $\begin{array}{c}0.16 \pm 0.0 \\
1\end{array}$ & $\begin{array}{c}0.07 \pm 0.0 \\
1\end{array}$ & $\begin{array}{c}1.77 \pm 0.1 \\
4\end{array}$ & $0.57 \pm 0.05$ & $\begin{array}{c}1.07 \pm 0.3 \\
8\end{array}$ & $4.62 \pm 0.62$ & $\begin{array}{c}0.70 \pm 0.0 \\
6\end{array}$ & $\begin{array}{c}0.29 \pm 0.0 \\
3\end{array}$ \\
\hline & $\mathrm{KO}(\mathrm{n}=2)$ & $\begin{array}{c}22.7 \pm 2 . \\
5\end{array}$ & $\begin{array}{c}21.4 \pm 2 . \\
0\end{array}$ & $\begin{array}{c}0.37 \pm 0.0 \\
5\end{array}$ & $\begin{array}{c}0.13 \pm 0.0 \\
4\end{array}$ & $0.24 \pm 0.02$ & $\begin{array}{c}1.50 \pm 0.1 \\
4\end{array}$ & $\begin{array}{c}0.15 \pm 0.0 \\
2\end{array}$ & $\begin{array}{c}0.06 \pm 0.0 \\
2\end{array}$ & $\begin{array}{c}1.74 \pm 0.4 \\
0\end{array}$ & $0.60 \pm 0.12$ & $\begin{array}{c}1.14 \pm 0.0 \\
0\end{array}$ & $6.99 \pm 0.03$ & $\begin{array}{c}0.69 \pm 0.0 \\
4\end{array}$ & $\begin{array}{c}0.27 \pm 0.0 \\
8\end{array}$ \\
\hline \multirow{2}{*}{$\begin{array}{c}\text { PCB } \\
91\end{array}$} & WT $(n=3)$ & $\begin{array}{c}23.8 \pm 2 . \\
2\end{array}$ & $\begin{array}{c}23.4 \pm 3 . \\
2\end{array}$ & $\begin{array}{c}0.41 \pm 0.0 \\
1\end{array}$ & $\begin{array}{c}0.13 \pm 0.0 \\
2\end{array}$ & $0.29 \pm 0.01$ & $\begin{array}{c}1.20 \pm 0.1 \\
6\end{array}$ & $\begin{array}{c}0.17 \pm 0.0 \\
3\end{array}$ & $\begin{array}{c}0.08 \pm 0.0 \\
1\end{array}$ & $\begin{array}{c}1.80 \pm 0.2 \\
7\end{array}$ & $0.55 \pm 0.02$ & $\begin{array}{c}1.25 \pm 0.1 \\
3\end{array}$ & $5.15 \pm 0.02$ & $\begin{array}{c}0.75 \pm 0.2 \\
4\end{array}$ & $\begin{array}{c}0.32 \pm 0.0 \\
1\end{array}$ \\
\hline & $\mathrm{KO}(\mathrm{n}=4)$ & $\begin{array}{c}23.1 \pm 1 . \\
5\end{array}$ & $\begin{array}{c}22.2 \pm 1 \\
6\end{array}$ & $\begin{array}{c}0.42 \pm 0.0 \\
2\end{array}$ & $0.11 \pm 0.01$ & $0.25 \pm 0.02$ & $\begin{array}{c}1.60 \pm 0.2 \\
4\end{array}$ & $\begin{array}{c}0.17 \pm 0.0 \\
2\end{array}$ & $\begin{array}{c}0.07 \pm 0.0 \\
1\end{array}$ & $\begin{array}{c}1.89 \pm 0.1 \\
3\end{array}$ & $0.50 \pm 0.02$ & $\begin{array}{c}1.15 \pm 0.0 \\
9\end{array}$ & $7.15 \pm 0.74$ & $\begin{array}{c}0.78 \pm 0.0 \\
7\end{array}$ & $\begin{array}{c}0.31 \pm 0.0 \\
5\end{array}$ \\
\hline
\end{tabular}

${ }^{\$}$ WT and KO mice received a single oral dose PCB 91 (30 mg/kg b.w.) on a Vanilla Wafer cookie (7.5 g/kg b.w.); WT and KO control groups received the vehicle (Vanilla Wafer cookie; $7.5 \mathrm{~g} / \mathrm{kg}$ b.w.) alone. ${ }^{*}$ Significantly different from WT $(\mathrm{p}<0.05)$ analyzed by Student's t-test; ${ }^{\&}$ calculated as organ weight $\times 100 /$ body weight; values are means \pm SD. 
Table S2: Concentrations of PCB 91 (ng/g wet weight) in tissues, blood, and excreta in WT and KO mice after oral administration of PCB 91.

\begin{tabular}{c|cc}
\hline Tissue & WT & KO \\
\hline Adipose & $92000 \pm 88000$ & $190000 \pm 60000$ \\
Blood & $90 \pm 50$ & $320 \pm 120^{*}$ \\
Brain & $570 \pm 400$ & $2800 \pm 1000^{*}$ \\
Liver & $1800 \pm 800$ & $44000 \pm 17000^{*}$ \\
\hline Feces (day 1) & $760 \pm 610$ & $8400 \pm 4700^{\$}$ \\
Feces (day 2) & $170 \pm 90$ & $730 \pm 290^{*}$ \\
Feces (day 3) & $190 \pm 170$ & $530 \pm 260$ \\
\hline Urine (day 1) & $1600 \pm 1300$ & $15000 \pm 6000^{*}$ \\
Urine (day 2) & $440 \pm 370$ & $6300 \pm 3200^{*}$ \\
Urine (day 3) & $270 \pm 290$ & $4200 \pm 1200^{*}$ \\
\hline
\end{tabular}

* Significantly different from WT $(p<0.05)$ analyzed by Student's t-test; $\$(0.05<=p<0.1)$ analyzed by Student's t-test; values are means $\pm \mathrm{SD}$. 
Table S3: Concentrations of OH-PCB 91 metabolites (ng/g wet weight) in tissues blood and excreta in WT and KO mice after oral administration of PCB 91.

\begin{tabular}{|c|c|c|c|c|c|c|c|c|c|}
\hline & \multirow{2}{*}{ Tissue } & \multicolumn{4}{|c|}{$\underline{\mathrm{WT}}$} & \multicolumn{4}{|c|}{$\underline{\mathrm{KO}}$} \\
\hline & & $3-100$ & $5-91$ & $4-91$ & $4,5-91$ & $3-100$ & $5-91$ & $4-91$ & $4,5-91$ \\
\hline \multirow{4}{*}{\multicolumn{2}{|c|}{$\begin{array}{l}\text { Adipose } \\
\text { Blood } \\
\text { Brain } \\
\text { Liver }\end{array}$}} & 1 & 1 & 1 & 1 & 1 & $130^{\dagger}$ & 1 & 1 \\
\hline & & $80 \pm 30$ & $40 \pm 20$ & $3 \pm 1$ & $13 \pm 8$ & $80 \pm 35$ & $43 \pm 37$ & $2 \pm 2$ & $18 \pm 10$ \\
\hline & & l & l & l & l & / & l & l & l \\
\hline & & $110 \pm 100$ & $1300 \pm 1600$ & $80 \pm 80$ & $30 \pm 30$ & $80 \pm 90$ & $1200 \pm 1300$ & $100 \pm 70$ & $50 \pm 50$ \\
\hline \multirow{3}{*}{ Feces } & Day 1 & $250 \pm 190$ & $20000 \pm 13000$ & $3600 \pm 1500$ & $520 \pm 350$ & $50 \pm 20$ & $16000 \pm 2800$ & $1600 \pm 420$ & $280 \pm 90$ \\
\hline & Day 2 & $80 \pm 40$ & $6900 \pm 4300$ & $1400 \pm 800$ & $230 \pm 110$ & $60 \pm 20$ & $6700 \pm 1100$ & $950 \pm 260$ & $240 \pm 50$ \\
\hline & Day 3 & $60 \pm 50$ & $8200 \pm 8800$ & $1700 \pm 1800$ & $220 \pm 180$ & $40 \pm 30$ & $4800 \pm 3400$ & $700 \pm 390$ & $180 \pm 50$ \\
\hline \multirow[b]{2}{*}{$\begin{array}{l}\text { Urine } \\
\text { (day 1) }\end{array}$} & without enzyme & 1 & $280 \pm 240$ & $27 \pm 30$ & $20 \pm 10$ & 1 & $1700 \pm 1100$ & $13 \pm 12$ & $13 \pm 9$ \\
\hline & $\begin{array}{l}\text { with enzyme } \\
\Delta^{*}\end{array}$ & l & $\begin{array}{l}430 \pm 310 \\
(80 \sim 240)\end{array}$ & $7 \pm 7$ & $\begin{array}{l}240 \pm 220 \\
(80 \sim 470) \\
\end{array}$ & / & $\begin{array}{c}2400 \pm 1100 \\
(0 \sim 140)\end{array}$ & $11 \pm 4$ & $\begin{array}{r}90 \pm 30^{\#} \\
(40 \sim 80) \\
\end{array}$ \\
\hline \multirow{3}{*}{$\begin{array}{l}\text { Urine } \\
\text { (day 2) }\end{array}$} & without enzyme & 1 & $40 \pm 30$ & 1 & $8 \pm 7$ & 1 & $370 \pm 210$ & $30 \pm 50$ & $5 \pm 3$ \\
\hline & with enzyme & I & $\begin{array}{l}130 \pm 30^{\#} \\
(p=0.08)\end{array}$ & / & $250 \pm 240$ & l & $420 \pm 230$ & l & $40 \pm 10^{\#}$ \\
\hline & $\Delta^{\star}$ & & $(20 \sim 170)$ & & $(50 \sim 510)$ & & $(0 \sim 110)$ & & $(0 \sim 50)$ \\
\hline \multirow[b]{2}{*}{$\begin{array}{l}\text { Urine } \\
\text { (day 3) }\end{array}$} & without enzyme & 1 & $170 \pm 230$ & 1 & $20 \pm 10$ & 1 & $340 \pm 200$ & 1 & $5 \pm 3$ \\
\hline & $\begin{array}{l}\text { with enzyme } \\
\Delta^{\ddagger}\end{array}$ & l & $\begin{array}{c}200 \pm 270 \\
(6 \sim 80)\end{array}$ & / & $\begin{array}{l}100 \pm 100 \\
(40 \sim 190)\end{array}$ & / & $\begin{array}{c}370 \pm 180 \\
(0 \sim 100)\end{array}$ & / & $\begin{array}{l}30 \pm 10^{\#} \\
(10 \sim 30)\end{array}$ \\
\hline
\end{tabular}

\# Significantly increased OH-PCB 91 levels after $\beta$-glucuronidase/sulfatase deconjugation; / lower than detection limit; ${ }^{\dagger}$ only one sample higher than $L O D ;{ }^{\star} \Delta(\mathrm{ng} / \mathrm{ml})=$ concentration with enzyme - concentration without enzyme; values are means $\pm \mathrm{SD}$. 
Table S4: Lipid adjusted concentrations of PCB 91 ( $\mu \mathrm{g} / \mathrm{g}$ lipid) in tissues and feces in WT and KO mice after oral administration of PCB 91.

\begin{tabular}{c|cc}
\hline Tissue & WT $(\mu \mathrm{g} / \mathrm{g}$ lipid $)$ & KO $(\mu \mathrm{g} / \mathrm{g}$ lipid $)$ \\
\hline Adipose & $110 \pm 100$ & $210 \pm 70$ \\
Brain & $6 \pm 4$ & $30 \pm 10^{*}$ \\
Liver & $20 \pm 10$ & $220 \pm 70^{*}$ \\
\hline Feces (day 1) & $30 \pm 20$ & $210 \pm 130$ \\
Feces (day 2) & $6 \pm 3$ & $20 \pm 10$ \\
Feces (day 3) & $8 \pm 6$ & $16 \pm 9$ \\
\hline
\end{tabular}

* Significantly different from WT $(\mathrm{p}<0.05)$ analyzed by Student's t-test; values are means \pm SD. 
Table S5: Concentrations of OH-PCB 91 ( $\mu \mathrm{g} / \mathrm{g}$ lipid) in tissues and feces in WT and KO mice after oral administration of PCB 91.

\begin{tabular}{|c|c|c|c|c|c|c|c|c|}
\hline \multirow{2}{*}{ Tissue } & \multicolumn{4}{|c|}{$\underline{\text { WT }(\mu \mathrm{g} / \mathrm{g} \text { lipid })}$} & \multicolumn{4}{|c|}{$\underline{\mathrm{KO}}(\mu \mathrm{g} / \mathrm{g}$ lipid $)$} \\
\hline & $3-100$ & $5-91$ & $4-91$ & $4,5-91$ & $3-100$ & $5-91$ & $4-91$ & $4,5-91$ \\
\hline Adipose & I & / & / & / & / & / & / & / \\
\hline Brain & / & / & / & / & / & / & / & / \\
\hline Liver & $0.5 \pm 0.5$ & $6 \pm 8$ & $0.4 \pm 0.4$ & $0.1 \pm 0.1$ & $0.2 \pm 0.2$ & $3 \pm 3$ & $0.3 \pm 0.2$ & $0.1 \pm 0.1$ \\
\hline $\begin{array}{c}\text { Feces } \\
\text { (day 1) }\end{array}$ & $50 \pm 40$ & $\begin{array}{c}1800 \pm 100 \\
0\end{array}$ & $70 \pm 40$ & $9 \pm 5$ & $8 \pm 3$ & $\begin{array}{c}1300 \pm 30 \\
0\end{array}$ & $27 \pm 7$ & $4 \pm 2$ \\
\hline $\begin{array}{c}\text { Feces } \\
\text { (day 2) }\end{array}$ & $17 \pm 9$ & $700 \pm 400$ & $30 \pm 20$ & $4 \pm 2$ & $10 \pm 5$ & $520 \pm 180$ & $15 \pm 5$ & $4 \pm 0$ \\
\hline $\begin{array}{c}\text { Feces } \\
\text { (day 3) }\end{array}$ & $14 \pm 12$ & $860 \pm 880$ & $34 \pm 36$ & $4 \pm 3$ & $8 \pm 6$ & $360 \pm 240$ & $12 \pm 9$ & $2 \pm 0$ \\
\hline
\end{tabular}

/ Lower than detection limit; values are means $\pm \mathrm{SD}$. 
Table S6: The amount of PCB 91 and OH-PCB 91 metabolites in tissue, blood, and excreta expressed as a percent of total dose in WT and KO mice after oral administration of PCB 91.

\begin{tabular}{|c|c|c|c|c|c|c|c|c|c|c|c|c|}
\hline \multirow{2}{*}{$\begin{array}{l}\text { Tissue } \\
\text { / Excreta }\end{array}$} & \multicolumn{6}{|c|}{$\underline{\mathrm{WT}}(\%$ of total dose) } & \multicolumn{6}{|c|}{$\underline{\mathrm{KO}(\% \text { of total dose })}$} \\
\hline & РCB 91 & $3-100$ & $5-91$ & $4-91$ & $4,5-91$ & total & PCB 91 & $3-100$ & $5-91$ & $4-91$ & $4,5-91$ & total \\
\hline Adipose $^{@}$ & $18 \pm 17$ & / & / & / & / & $18 \pm 17$ & $37 \pm 12$ & / & / & / & / & $37 \pm 12$ \\
\hline Blood $^{@}$ & $0.02 \pm 0.01$ & $0.01 \pm 0.00$ & $\begin{array}{c}0.007 \pm 0.00 \\
3\end{array}$ & / & $\begin{array}{c}0.002 \pm 0.00 \\
1\end{array}$ & $0.4 \pm 0.2$ & $0.06 \pm 0.02^{*}$ & $0.01 \pm 0.01$ & $\begin{array}{c}0.008 \pm 0.00 \\
7\end{array}$ & / & $\begin{array}{c}0.003 \pm 0.00 \\
2\end{array}$ & $0.9 \pm 0.3^{\$}$ \\
\hline Brain & $0.3 \pm 0.3$ & / & / & / & / & $0.3 \pm 0.3$ & $1.7 \pm 0.7^{*}$ & / & / & / & / & $2 \pm 1^{*}$ \\
\hline Liver & $0.3 \pm 0.1$ & $0.02 \pm 0.01$ & $0.2 \pm 0.2$ & $0.01 \pm 0.01$ & $\begin{array}{c}0.004 \pm 0.00 \\
4\end{array}$ & $0.5 \pm 0.4$ & $9 \pm 4^{*}$ & $0.01 \pm 0.01$ & $0.2 \pm 0.2$ & $0.02 \pm 0.01$ & $\begin{array}{c}0.006 \pm 0.00 \\
6\end{array}$ & $9 \pm 4^{*}$ \\
\hline Feces(day 1) & $0.3 \pm 0.2$ & $0.5 \pm 0.3$ & $17 \pm 6$ & $0.7 \pm 0.3$ & $0.08 \pm 0.03$ & $19 \pm 7$ & $3 \pm 2^{\$}$ & $0.07 \pm 0.02$ & $12 \pm 2$ & $0.3 \pm 0.1$ & $0.04 \pm 0.01$ & $16 \pm 3$ \\
\hline Feces(day 2) & $0.09 \pm 0.06$ & $0.2 \pm 0.2$ & $9 \pm 7$ & $0.4 \pm 0.3$ & $0.05 \pm 0.03$ & $10 \pm 7$ & $0.3 \pm 0.1^{*}$ & $0.1 \pm 0.0$ & $6 \pm 1$ & $0.2 \pm 0.0$ & $0.04 \pm 0.01$ & $7 \pm 1$ \\
\hline Feces(day 3) & $0.05 \pm 0.01$ & $0.09 \pm 0.02$ & $5 \pm 2$ & $0.2 \pm 0.1$ & $0.03 \pm 0.01$ & $5 \pm 2$ & $0.2 \pm 0.1^{*}$ & $0.08 \pm 0.03$ & $4 \pm 1$ & $0.1 \pm 0.1$ & $0.03 \pm 0.00$ & $5 \pm 1$ \\
\hline Feces (total) & $0.4 \pm 0.2$ & $0.8 \pm 0.4$ & $31 \pm 14$ & $1 \pm 1$ & $0.2 \pm 0.1$ & $34 \pm 15$ & $4 \pm 2^{\$}$ & $0.3 \pm 0.1$ & $23 \pm 4$ & $0.6 \pm 0.1$ & $0.1 \pm 0.0$ & $27 \pm 6$ \\
\hline $\begin{array}{l}\text { Urine } \\
(\text { day } 1)^{\&}\end{array}$ & $0.2 \pm 0.1$ & $\begin{array}{c}0.001 \pm 0.00 \\
1\end{array}$ & $0.05 \pm 0.02$ & $\begin{array}{c}0.001 \pm 0.00 \\
0\end{array}$ & $0.03 \pm 0.01$ & $0.3 \pm 0.1$ & $2 \pm 1^{*}$ & / & $0.3 \pm 0.3$ & $\begin{array}{c}0.001 \pm 0.00 \\
1\end{array}$ & $0.01 \pm 0.01$ & $2 \pm 1^{*}$ \\
\hline $\begin{array}{c}\text { Urine } \\
(\text { day } 2)^{\&}\end{array}$ & $0.06 \pm 0.03$ & $\begin{array}{c}0.001 \pm 0.00 \\
0\end{array}$ & $0.02 \pm 0.00$ & / & $0.03 \pm 0.02$ & $0.1 \pm 0.1$ & $1.1 \pm 0.2^{*}$ & / & $0.08 \pm 0.06$ & / & $0.01 \pm 0.01$ & $1.2 \pm 0.3^{*}$ \\
\hline $\begin{array}{c}\text { Urine } \\
(\text { day } 3)^{\&}\end{array}$ & $0.02 \pm 0.00$ & / & $0.01 \pm 0.01$ & / & $0.01 \pm 0.00$ & $0.04 \pm 0.01$ & $0.8 \pm 0.1^{*}$ & / & $0.07 \pm 0.04$ & / & $\begin{array}{c}0.005 \pm 0.00 \\
2\end{array}$ & $0.9 \pm 0.2^{*}$ \\
\hline Urine (total) & $0.3 \pm 0.1$ & $\begin{array}{c}0.002 \pm 0.00 \\
1 \\
\end{array}$ & $0.08 \pm 0.02$ & $\begin{array}{c}0.001 \pm 0.00 \\
0 \\
\end{array}$ & $0.06 \pm 0.03$ & $0.4 \pm 0.2$ & $4 \pm 1^{*}$ & / & $0.4 \pm 0.4$ & $\begin{array}{c}0.002 \pm 0.00 \\
1 \\
\end{array}$ & $0.02 \pm 0.01$ & $4 \pm 1^{*}$ \\
\hline Total & $20 \pm 18$ & $0.8 \pm 0.4$ & $31 \pm 14$ & $1.3 \pm 0.6$ & $0.2 \pm 0.1$ & $53 \pm 33$ & $55 \pm 17^{\$}$ & $0.3 \pm 0.1$ & $23 \pm 5$ & $0.6 \pm 0.1$ & $0.2 \pm 0.1$ & $80 \pm 22$ \\
\hline
\end{tabular}

${ }^{\circledR}$ The percentage of body weight was assumed to be $5.9 \%$ b.w. for adipose and $5.85 \%$ b.w. for blood; $;=$ \& calculated based on the total amount of PCB 91 and/or OH-PCB 91 determined after $\beta$-glucuronidase/sulfatase deconjugation; / lower than detection limit; * significantly different from WT (p<0.05) analyzed by Student's t-test; ${ }^{\$} 0.05 \leq \mathrm{p}<0.1$ analyzed by Student's t-test; values are means $\pm \mathrm{SD}$. 
Table S7: Comparison of the enantiomeric fraction (EF) of the PCB 91 and its metabolites, 5-91 and 4-91, in tissues and excreta in WT and KO mice after oral administration of PCB $91 .^{\text {a }}$

\begin{tabular}{|c|c|c|c|c|c|c|c|c|c|c|}
\hline \multirow{3}{*}{$\begin{array}{c}\text { Tissue/Extret } \\
\mathrm{a}\end{array}$} & \multicolumn{5}{|c|}{ WT mice } & \multicolumn{5}{|c|}{ KO mice } \\
\hline & \multicolumn{2}{|c|}{$\underline{\text { PCB } 91}$} & $4-91$ & \multicolumn{2}{|c|}{$\underline{5-91}$} & \multicolumn{2}{|c|}{$\underline{\text { PCB } 91}$} & $4-91$ & \multicolumn{2}{|c|}{$\underline{5-91}$} \\
\hline & $\mathrm{BDM}$ & $\mathrm{CD}$ & $\mathrm{BDM}$ & $\mathrm{BDM}$ & $\mathrm{CD}$ & $\mathrm{BDM}$ & $\mathrm{CD}$ & BDM & BDM & $\mathrm{CD}$ \\
\hline Adipose & $\begin{array}{c}0.74 \pm 0.0 \\
1\end{array}$ & - & l & l & l & $\underset{*}{0.60 \pm 0.00}$ & - & / & l & l \\
\hline Blood & $\begin{array}{c}0.89 \pm 0.0 \\
1\end{array}$ & $\begin{array}{c}0.10 \pm 0.0 \\
0\end{array}$ & $\begin{array}{c}0.92 \pm 0.0 \\
5\end{array}$ & $\begin{array}{c}0.90 \pm 0.0 \\
1\end{array}$ & $\begin{array}{c}0.89 \pm 0.0 \\
1\end{array}$ & $\underset{*}{0.67 \pm 0.01}$ & $\underset{*}{0.32 \pm 0.01}$ & $0.88 \pm 0.08$ & $\underset{*}{0.70 \pm 0.08}$ & $\underset{*}{0.73 \pm 0.05}$ \\
\hline Brain & $\begin{array}{c}0.90 \pm 0.0 \\
3\end{array}$ & - & I & l & l & $\underset{*}{0.69 \pm 0.02}$ & - & / & / & / \\
\hline Liver & $\begin{array}{c}0.94 \pm 0.0 \\
2 \\
\end{array}$ & $\begin{array}{c}0.06 \pm 0.0 \\
2 \\
\end{array}$ & $\begin{array}{c}1.00 \pm 0.0 \\
0 \\
\end{array}$ & $\begin{array}{c}0.77 \pm 0.0 \\
2 \\
\end{array}$ & $\begin{array}{c}0.79 \pm 0.0 \\
1 \\
\end{array}$ & $\underset{*}{0.69 \pm 0.01}$ & $\underset{*}{0.31 \pm 0.02}$ & $\underset{\$}{0.83 \pm 0.12}$ & $\begin{array}{c}0.47 \pm 0.07 \\
*\end{array}$ & $\underset{*}{0.51 \pm 0.05}$ \\
\hline Feces (day 1) & $\begin{array}{c}0.65 \pm 0.0 \\
3\end{array}$ & $\begin{array}{c}0.36 \pm 0.0 \\
2\end{array}$ & $\begin{array}{c}0.65 \pm 0.0 \\
4\end{array}$ & $\begin{array}{c}0.38 \pm 0.0 \\
2\end{array}$ & $\begin{array}{c}0.38 \pm 0.0 \\
2\end{array}$ & $\underset{*}{0.54 \pm 0.02}$ & $\underset{*}{0.47 \pm 0.03}$ & $0.64 \pm 0.01$ & $\underset{*}{0.24 \pm 0.03}$ & $\underset{*}{0.24 \pm 0.03}$ \\
\hline Feces (day 2) & $\begin{array}{c}0.85 \pm 0.0 \\
2\end{array}$ & $\begin{array}{c}0.19 \pm 0.0 \\
6\end{array}$ & $\begin{array}{c}0.88 \pm 0.0 \\
3\end{array}$ & $\begin{array}{c}0.66 \pm 0.0 \\
4\end{array}$ & $\begin{array}{c}0.65 \pm 0.0 \\
5\end{array}$ & $\underset{*}{0.67 \pm 0.01}$ & $\underset{*}{0.36 \pm 0.01}$ & $\underset{*}{0.74 \pm 0.04}$ & $\underset{*}{0.40 \pm 0.02}$ & $\underset{*}{0.38 \pm 0.01}$ \\
\hline Feces (day 3) & $\begin{array}{c}0.88 \pm 0.0 \\
0 \\
\end{array}$ & $\begin{array}{c}0.14 \pm 0.0 \\
1 \\
\end{array}$ & $\begin{array}{c}0.92 \pm 0.0 \\
0 \\
\end{array}$ & $\begin{array}{c}0.73 \pm 0.0 \\
2 \\
\end{array}$ & $\begin{array}{c}0.73 \pm 0.0 \\
2 \\
\end{array}$ & $\begin{array}{c}0.72 \pm 0.02 \\
*\end{array}$ & $\begin{array}{c}0.34 \pm 0.04 \\
*\end{array}$ & $\begin{array}{c}0.79 \pm 0.02 \\
*\end{array}$ & $\underset{*}{0.47 \pm 0.01}$ & $\begin{array}{c}0.45 \pm 0.02 \\
*\end{array}$ \\
\hline Urine (day 1) & - & $\begin{array}{c}0.40 \pm 0.0 \\
1\end{array}$ & / & - & $\begin{array}{c}0.19 \pm 0.0 \\
5\end{array}$ & - & $\underset{*}{0.63 \pm 0.06}$ & / & - & $0.08 \pm 0.08$ \\
\hline$\underset{\dagger}{\text { Urine (day 2) }}$ & - & $\begin{array}{c}0.23 \pm 0.0 \\
3\end{array}$ & I & - & $\begin{array}{c}0.43 \pm 0.0 \\
9\end{array}$ & - & $\underset{*}{0.61} \underset{*}{ \pm 0.04}$ & / & - & $\underset{*}{0.13} \pm 0.12$ \\
\hline$\underset{+}{\text { Urine (day 3) }}$ & - & $\begin{array}{c}0.29 \pm 0.0 \\
4\end{array}$ & / & - & $\begin{array}{c}0.56 \pm 0.1 \\
2\end{array}$ & - & $\underset{*}{0.58 \pm 0.04}$ & I & - & $\underset{*}{0.19 \pm 0.14}$ \\
\hline
\end{tabular}

${ }^{a} \mathrm{EF}$ values were determined separately using the formula $\mathrm{EF}=$ Area $_{\mathrm{E}(1)} /\left(\mathrm{Area}_{\mathrm{E}(1)}+\right.$ Area $\left._{\mathrm{E}(2)}\right)$ on ChiralDex BDM (BDM) and CP-ChiraSil-DEX CB (CD) columns (note: the elution order of PCB 91 atropisomers is inverted on the BDM and CD column,,$^{14}$ resulting in different EF values here; however, the same PCB 91 atropisomer is enriched); ${ }^{\dagger}$ data from pooled samples with or without $\beta$-glucuronidase/sulfatase 
deconjugation; - not determined on this column; / lower than detection limit; * significantly different from WT (p<0.05) analyzed by Student's ttest; ${ }^{\$} 0.05 \leq \mathrm{p}<0.1$ analyzed by Student's t-test; values are means \pm SD. 
Table S8: Limits of detection ( $L O D S$ ) and background levels of PCB 91 and its metabolites in tissues from mice dosed with vehicle alone. Background levels are adjusted by wet weight or extracted dry lipid content."

\begin{tabular}{|c|c|c|c|c|c|c|}
\hline \multicolumn{2}{|c|}{ PCBs } & PCB 91 & $3-100$ & $5-91$ & $4-91$ & $4,5-91$ \\
\hline \multicolumn{2}{|c|}{$L O D[n g]^{*}$} & 2.7 & 0.7 & 17 & 7.6 & 2.4 \\
\hline \multirow{6}{*}{$\begin{array}{c}\text { Background } \\
\text { levels adjusted } \\
\text { by wet weight } \\
{[\mathrm{ng} / \mathrm{g}]}\end{array}$} & Adipose & $96 \pm 46$ & $3.1 \pm 2.5$ & $5.5 \pm 7.7$ & $15 \pm 28$ & $1.4 \pm 1.7$ \\
\hline & Brain & $11 \pm 1$ & $1.0 \pm 1.1$ & $4.2 \pm 0.6$ & $0.4 \pm 0.5$ & 0 \\
\hline & Liver & $10 \pm 5$ & $0.4 \pm 0.3$ & $0.5 \pm 0.4$ & $0.4 \pm 0.1$ & $0.4 \pm 0.2$ \\
\hline & Feces (day 1) & $9.2 \pm 1.1$ & $2.8 \pm 0.6$ & $8.0 \pm 1.8$ & $1.8 \pm 1.8$ & $0.9 \pm 0.5$ \\
\hline & Feces (day 2) & $6.2 \pm 0.6$ & $1.4 \pm 0.1$ & $7.8 \pm 2.9$ & $0.6 \pm 0.9$ & $0.8 \pm 1.3$ \\
\hline & Feces (day 3) & $5.5 \pm 1.1$ & $1.5 \pm 0.2$ & $5.4 \pm 2.7$ & $0.6 \pm 0.6$ & $0.6 \pm 0.8$ \\
\hline \multirow{6}{*}{$\begin{array}{c}\text { Background } \\
\text { levels adjusted } \\
\text { by lipid weight } \\
{[\mu \mathrm{g} / \mathrm{g}]}\end{array}$} & Adipose & $0.11 \pm 0.05$ & $0.003 \pm 0.003$ & $0.006 \pm 0.008$ & $0.02 \pm 0.03$ & $0.002 \pm 0.002$ \\
\hline & Brain & $0.12 \pm 0.01$ & $0.009 \pm 0.003$ & $0.01 \pm 0.01$ & $0.007 \pm 0.004$ & $0.004 \pm 0.003$ \\
\hline & Liver & $0.09 \pm 0.09$ & $0.004 \pm 0.004$ & $0.004 \pm 0.002$ & $0.003 \pm 0.003$ & $0.004 \pm 0.004$ \\
\hline & Feces (day 1) & $0.33 \pm 0.11$ & $0.10 \pm 0.01$ & $0.28 \pm 0.08$ & $0.07 \pm 0.09$ & $0.03 \pm 0.02$ \\
\hline & Feces (day 2) & $0.12 \pm 0.00$ & $0.03 \pm 0.00$ & $0.15 \pm 0.07$ & $0.01 \pm 0.02$ & $0.01 \pm 0.02$ \\
\hline & Feces (day 3) & $0.12 \pm 0.02$ & $0.03 \pm 0.00$ & $0.12 \pm 0.07$ & $0.01 \pm 0.01$ & $0.01 \pm 0.02$ \\
\hline
\end{tabular}

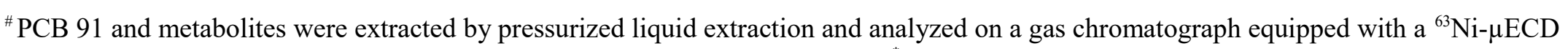
detector, as described under Experimental Procedures. Values are means \pm SD. ${ }^{*}$ The $L O D$ s were calculated based on blank samples containing Florisil and diatomaceous earth only. The blank samples were analyzed in parallel with tissue samples. The LODs were calculated as 
$L O D=\overline{x_{b}}+k \cdot s_{b}$, where $\overline{x_{b}}$ is mean of all blank samples, $k$ is Student's t-value for $\mathrm{n}-1$ degrees of freedom at $99 \%$ confidence level, and $s_{b}$ is the standard deviation of the blank measures. ${ }^{1}$

Table S9: Limits of detection (LODs) and background levels of PCB 91 and its metabolites in blood and urine from animals dosed with vehicle alone."

\begin{tabular}{|c|c|c|c|c|c|c|}
\hline \multicolumn{2}{|c|}{ PCBs } & PCB 91 & $3-100$ & $5-91$ & $4-91$ & $4,5-91$ \\
\hline \multicolumn{2}{|c|}{$L O D[n g]^{*}$} & 3.80 & 0.27 & 0.42 & 0.42 & 0.80 \\
\hline \multirow{2}{*}{$\begin{array}{l}\text { Background } \\
\text { levels }[\mathrm{ng} / \mathrm{g}]\end{array}$} & Blood & $1.19 \pm 0.18$ & $0.08 \pm 0.05$ & $0.32 \pm 0.19$ & $0.19 \pm 0.08$ & $0.05 \pm 0.03$ \\
\hline & Urine & $0.90 \pm 0.28$ & $0.03 \pm 0.06$ & $0.11 \pm 0.07$ & $0.34 \pm 0.68$ & $0.30 \pm 0.05$ \\
\hline
\end{tabular}

${ }^{\#}$ PCB 91 and metabolites were extracted by pressurized liquid extraction and analyzed on a gas chromatograph equipped with a ${ }^{63} \mathrm{Ni}-\mu \mathrm{ECD}$ detector, as described under Experimental Procedures. Values are means \pm SD. ${ }^{*}$ The $L O D$ s for blood and urine samples were calculated based on blank samples containing buffer only. The blank samples were analyzed in parallel with the respective blood or urine samples. The $L O D$ s were

calculated as $L O D=\overline{x_{b}}+k \cdot s_{b}$, where $\overline{X_{b}}$ is mean of all blank samples, $k$ is Student's t-value for n-1 degrees of freedom at $99 \%$ confidence level, and $s_{b}$ is the standard deviation of the blank measures. ${ }^{1}$ 
Table S10: Extractable lipid content expressed as a percent of tissue or feces wet weight (\%) in PCB 91 or vehicle-treated WT and KO mice. ${ }^{\$}$

\begin{tabular}{|c|c|c|c|c|c|c|c|}
\hline Mice & Dose & Adipose & Brain & Liver & Feces (day 1) & Feces (day 2) & Feces (day 3) \\
\hline \multirow{3}{*}{ WT } & $\begin{array}{c}\text { Vehicle } \\
(n=2)\end{array}$ & $86.7 \pm 0.4$ & $9.8 \pm 0.1$ & $9.1 \pm 2.0$ & $4.9 \pm 1.2$ & $4.9 \pm 0.4$ & $4.3 \pm 0.3$ \\
\hline & $\begin{array}{c}\text { PCB 91 } \\
(n=3)\end{array}$ & $88.4 \pm 3.6$ & $9.2 \pm 0.6$ & $10.8 \pm 1.5$ & $5.2 \pm 0.7$ & $5.1 \pm 0.2$ & $4.6 \pm 0.3$ \\
\hline & $\begin{array}{c}\text { Combined } \\
\quad(\mathrm{n}=5)\end{array}$ & $87.8 \pm 2.7$ & $9.4 \pm 0.6$ & $10.1 \pm 1.7$ & $5.1 \pm 0.8$ & $5.0 \pm 0.3$ & $4.5 \pm 0.3$ \\
\hline \multirow{3}{*}{$\mathrm{KO}$} & $\begin{array}{c}\text { Vehicle } \\
(n=2)\end{array}$ & $95.5 \pm 3.1$ & $9.0 \pm 0.1$ & $21.8 \pm 2.4^{*}$ & $6.1^{\dagger}$ & $5.7^{\dagger}$ & $5.4^{\dagger}$ \\
\hline & $\begin{array}{c}\text { PCB } 91 \\
(\mathrm{n}=4)\end{array}$ & $90.8 \pm 3.4$ & $9.1 \pm 0.2$ & $20.3 \pm 3.8^{*}$ & $6.2 \pm 0.5$ & $6.1 \pm 0.5^{\#}$ & $5.9 \pm 0.5^{*}$ \\
\hline & $\begin{array}{c}\text { Combined } \\
(\mathrm{n}=6)\end{array}$ & $92.3 \pm 3.8^{*}$ & $9.0 \pm 0.2$ & $20.8 \pm 3.2^{*}$ & $6.2 \pm 0.4^{*}$ & $6.0 \pm 0.4^{*}$ & $5.7 \pm 0.5^{*}$ \\
\hline
\end{tabular}

\footnotetext{
${ }^{\$}$ Lipids were extracted from tissue and feces samples by pressurized liquid extraction, and lipid weights were determined gravimetrically as described under Experimental Procedures. * Significantly different from WT $(\mathrm{p}<0.05)$ analyzed by Student's t-test; ${ }^{*} \mathrm{p}=0.05 \mathrm{compared}$ to WT; $\dagger$ mice were housed together; values are means \pm SD.
} 


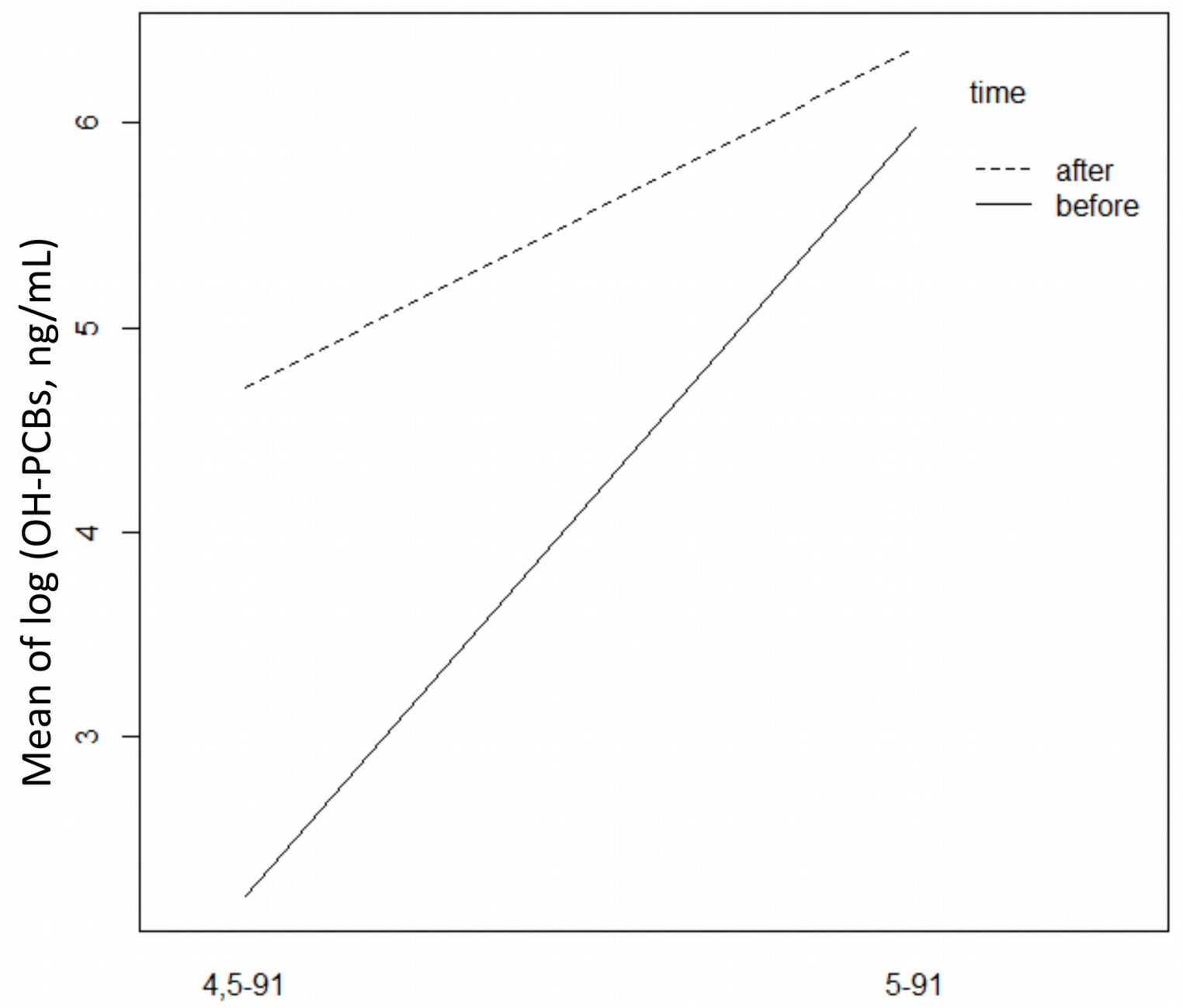

Figure S1: Increased concentration of 5-91 and 4,5-91 in day 1 urine after $\beta$ glucuronidase/sulfatase treatment. The data are the average of the concentration after combining data from WT and KO mice (Table S3 for more information) analyzed using an interaction plot with the statistical software R (i386 3.0.2). 


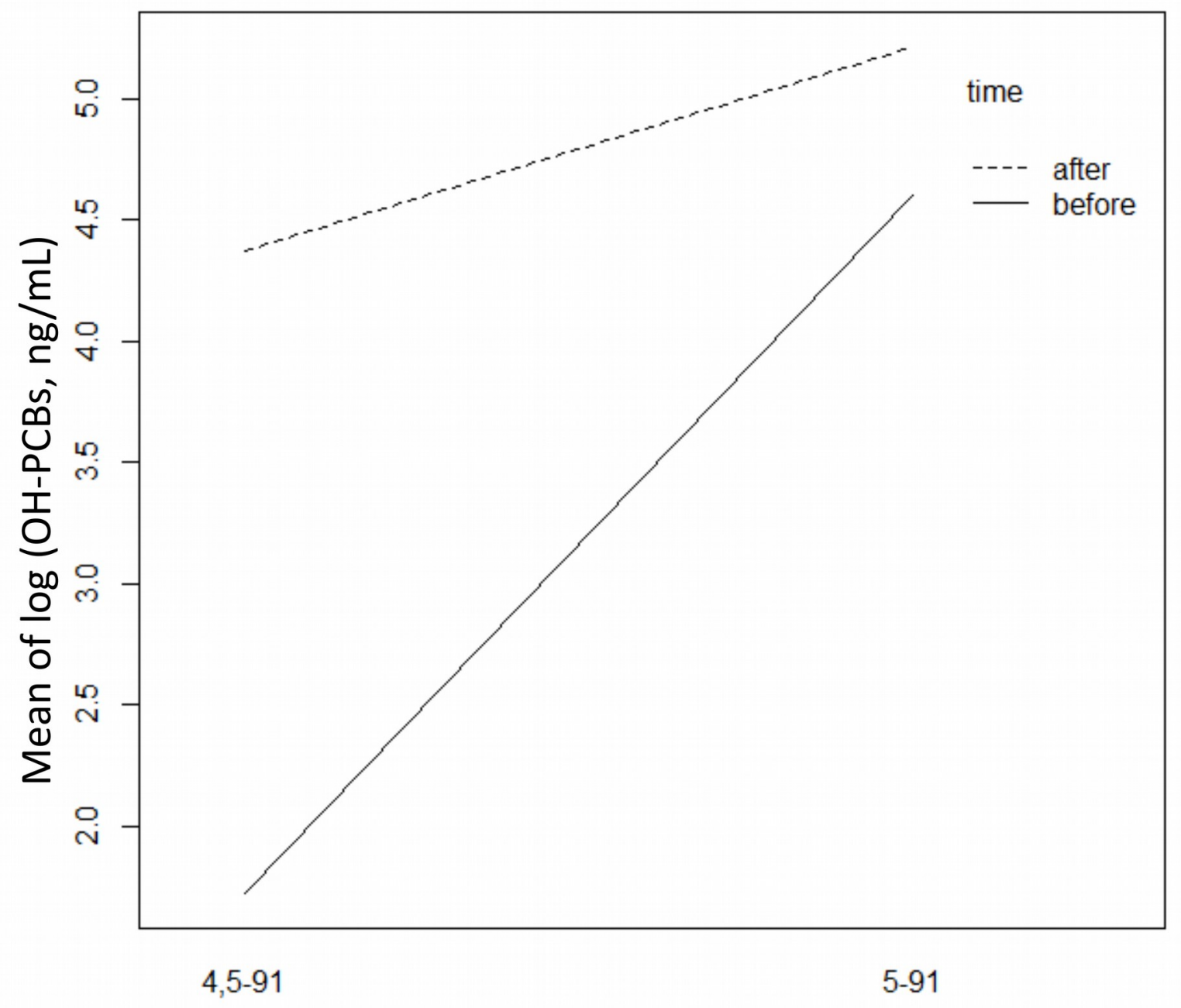

Figure S2: Increased concentration of 5-91 and 4,5-91 in day 2 urine after $\beta$ glucuronidase/sulfatase treatment. The data are the average of the concentration after combining data from WT and KO mice (Table S3 for more information) analyzed using an interaction plot with the statistical software R (i386 3.0.2). 


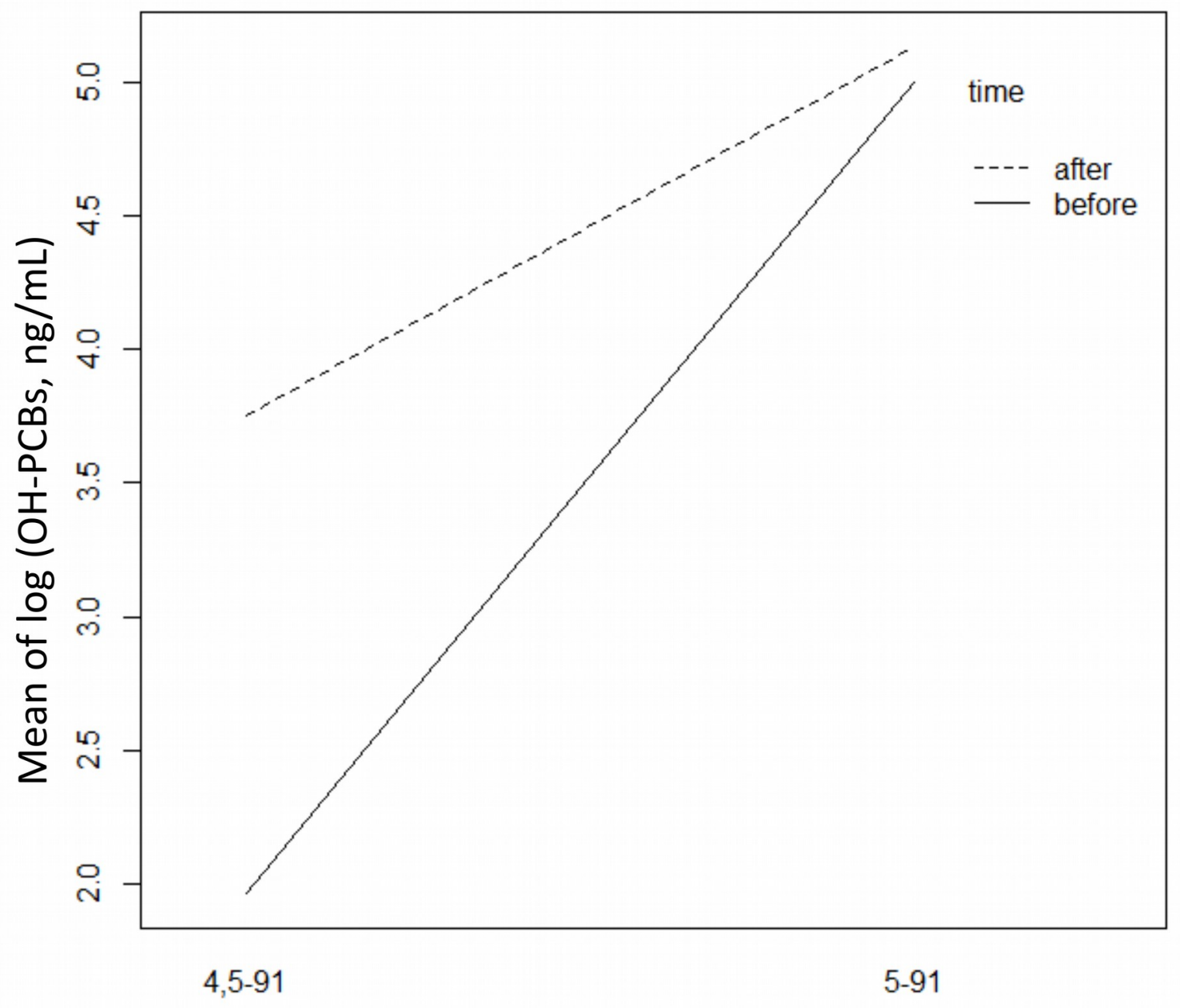

Figure S3: Increased concentration of 5-91 and 4,5-91 in day 3 urine after $\beta$ glucuronidase/sulfatase treatment. The data are the average of the concentration after combining data from WT and KO mice (Table S3 for more information) analyzed using an interaction plot with the statistical software R (i386 3.0.2). 


\section{References}

(1) Kania-Korwel, I., Shaikh, N., Hornbuckle, K. C., Robertson, L. W., and Lehmler, H.-J., Enantioselective disposition of PCB 136 (2,2',3,3',6,6'-hexachlorobiphenyl) in C57BL/6 mice after oral and intraperitoneal administration. Chirality. 2007, 19, 56-66.

(2) Kania-Korwel, I., Xie, W., Hornbuckle, K. C., Robertson, L. W., and Lehmler, H.-J., Enantiomeric enrichment of 2,2',3,3',6,6'-hexachlorobiphenyl (PCB 136) in mice after induction of CYP enzymes. Arch. Environ. Contam. Toxicol. 2008, 55, 510-517. 
SI PCB91 dispostion study in CPR null mice 06-03-201... (139.98 KiB) view on ChemRxiv • download file 